\title{
Molecular basis for the regulation of human glycogen synthase by phosphorylation and glucose-6-phosphate
}

\author{
Thomas J. McCorvie ${ }^{1,6}$, Paula M. Loria ${ }^{2}$, Meihua Tu ${ }^{3}$, Seungil Han ${ }^{4}$, Leela Shrestha ${ }^{1}$, D. \\ Sean Froese ${ }^{1,5}$, Igor M. Ferreira ${ }^{1}$, Allison P. Berg ${ }^{2}{ }^{\otimes}, W_{y a t t}$ W. Yue ${ }^{1,6 凶}$ \\ ${ }^{1}$ Centre for Medicines Discovery, Nuffield Department of Clinical Medicine, University of \\ Oxford, Oxford OX3 7DQ, UK \\ ${ }^{2}$ Rare Disease Research Unit, Worldwide Research and Development, Pfizer Inc., 610 Main \\ Street, Cambridge, MA 02139, USA \\ ${ }^{3}$ Pfizer Inc. Medicine Design, Cambridge, Massachusetts 02139, USA \\ ${ }^{4}$ Discovery Sciences, Worldwide Research and Development, Pfizer Inc., Eastern Point Road, \\ Groton, CT 06340, USA \\ ${ }^{5}$ Present address: Division of Metabolism and Children's Research Center, University \\ Children's Hospital Zürich, University of Zürich, Switzerland \\ ${ }^{6}$ Present address: Biosciences Institute, The Medical School, Newcastle University, Newcastle \\ upon Tyne, NE2 4HH, UK \\ 凶e-mail: allison.berg@pfizer.com; wyatt.yue@cmd.ox.ac.uk
}

Glycogen synthase (GYS1), in complex with glycogenin (GYG1), is the central enzyme of muscle glycogen biosynthesis, and its inhibition has been proposed as a therapeutic avenue for various glycogen storage diseases (GSDs). GYS1 activity is inhibited by phosphorylation of its N- and Ctermini, which can be relieved by allosteric activation of glucose-6-phosphate. However, the structural basis of GYS1 regulation is unclear. Here, we present the first cryo-EM structures of phosphorylated human GYS1 complexed with a minimal interacting region of GYG1 in the inhibited, activated, and catalytically competent states at resolutions of 3.0-4.0 $\AA$. These structures reveal how phosphorylations of specific $\mathrm{N}$ - and $\mathrm{C}$ - terminal residues are sensed by different arginine clusters that lock the GYS1 tetramer complex in an inhibited state via intersubunit interactions. The allosteric activator, glucose-6-phopshate, promotes a conformational change by disrupting these interactions and increases flexibility of GYS1 allowing for a catalytically competent state to occur when bound to the sugar donor UDP-glucose. We also identify an inhibited-like conformation that has not transitioned into the activated state, whereby the locking interaction of phosphorylation with the arginine cluster impedes the subsequent conformational changes due to glucose-6-phosphate binding. Finally, we show that the PP1 phosphatase regulatory subunit PPP1R3C (PTG) is recruited to the GYS1:GYG1 complex through direct interaction with glycogen. Our data provide the first mechanistic insights into human glycogen synthase regulation.

Glycogen serves as the main carbohydrate store and energy reserve across animal phyla and contains up to 55,000 glucose units linked by $\alpha-1,4$ and $\alpha-1,6$ glucosidic bonds ${ }^{1}$. Glycogen biosynthesis is catalyzed by the concerted actions of three enzymes in eukaryotes: (i) glycogenin (GYG, EC 2.4.1.186), which forms a short primer through stepwise attachment of glucose units onto itself'; (ii) glycogen synthase (GYS, EC 2.4.1.11), which "strings" glucose units to elongate the GYG-attached primer"; and (iii) glycogen branching enzyme (GBE, EC 2.4.1.18), which introduces branch points to a linear chain via $\alpha-1,6$ linkages ${ }^{4}$. In mammals, glycogen is primarily stored in the liver (for regulating glucose homeostasis during fasting) and muscle (as an energy reserve during exercise).

Bulk glycogen synthesis is carried out by GYS, a retaining glycosyltransferase (GT) belonging to the GT3 superfamily. GYS catalyses the successive addition of $\alpha-1,4-$ linked glucose residues to the non-reducing end of a growing polysaccharide chain, using UDP-glucose (UDP-glc) as the glucose donor with the release of UDP ${ }^{5}$. In mammals, GYS is present as two isoforms, GYS1 and GYS2, sharing $\sim 69 \%$ sequence identity ${ }^{6}$. GYS1 is expressed in most tissues including the muscle and brain ${ }^{7}$, while GYS2 is expressed only in the liver. Mammalian GYS is the rate-limiting enzyme in glycogen 
bioRxiv preprint doi: https://doi.org/10.1101/2021.11.12.468446; this version posted November 13, 2021. The copyright holder for this preprint (which was not certified by peer review) is the author/funder, who has granted bioRxiv a license to display the preprint in perpetuity. It is made available under aCC-BY 4.0 International license.

Structural Basis of Human GYS1 Regulation

biosynthesis, and its activity is regulated post-translationally by two mechanisms: activation by the effector glucose-6-phosphate (Glc6P) $)^{8,9}$ and inhibition by reversible phosphorylation ${ }^{10}$.

Reversible phosphorylation of GYS is mediated by several Ser/Thr-directed protein kinases, occurs at multiple sites, and is hierarchal in that different sites contribute to GYS inhibition in a specific order and to varying degrees ${ }^{11}$. At least 9 in vivo phosphorylation sites have been identified at the Nand C-termini of mammalian GYS1, in which sites 2 (Ser8), 2a (Ser11), 3a (Ser641), and 3b (Ser645) are found to play more significant roles ${ }^{12,13}$. Dephosphorylation, performed by glycogen-associated phosphatases of type 1 (PP1), significantly alters GYS kinetic properties such as increased affinity for UDP-glc and sensitivity to the Glc6P activator ${ }^{14}$. Glc6P binds to an allosteric site equipped with an arginine cluster, overcomes phosphorylation-dependent inhibition, and increases the enzyme's susceptibility to PP1-mediated dephosphorylation. These two regulatory mechanisms of mammalian GYS have been described by a three-state conformational model, comprising the Tense (T)/inhibited state where GYS is phosphorylated, Intermediate (I)/basal state when unphosphorylated, and Relaxed $(\mathrm{R}) /$ activated state when Glc6P is bound ${ }^{15-18}$.

The pleiotropic PP1 comprises a catalytic subunit (PP1c) and a regulatory subunit (PP1r), the latter targeting the phosphatase to specific targets. 7 glycogen-targeting PP1r (PPP1R3A - PPP1R3G), characterised by the presence of an RVSF motif for PP1c binding, a glycogen-binding motif VxNxxFEKxV and a putative GYS binding motif WxNxGxNYx(I/L), have been described ${ }^{19-21}$. Among them, subunit 3C (PPP1R3C; also known as protein targeting to glycogen, PTG) is ubiquitously expressed in the brain, liver, and heart, and its gene knockout indirectly reduces GYS activation ${ }^{22}$. As such, these PP1 regulatory subunits are often considered activators of GYS1, although direct interaction between these proteins has not been definitively shown. Nevertheless, PTG is thought to function as a scaffold for glycogen metabolic enzymes, such as GYS, glycogen phosphorylase, and phosphorylase kinase $^{22}$.

GYS1 has emerged as a therapeutic target for several glycogen storage diseases (GSD), including GSD type II (Pompe disease), GSD type IV (Andersen disease and adult polyglucosan body disease) and Lafora disease. The root of these disorders is the accumulation of aberrant or normal glycogen in affected tissues, due to defective glycogen synthesis or breakdown. Downregulating GYS1 activity to interfere with glycogen chain elongation therefore could present a therapeutic opportunity. Despite this, inhibitor development for GYS1 has not progressed rapidly ${ }^{23,24}$, in part due to a lack of structural data, beyond that from bacterial ${ }^{25-27}, S$. cerevisiae ${ }^{16}$ and C. elegans ${ }^{28}$ GYS orthologues, to guide drug discovery efforts. In this study we used cryo-electron microscopy (cryo-EM) to determine the structure of phosphorylated human GYS1 in different functional states and characterized the interactions with its functional partners, namely glycogenin GYG1 and the PP1 regulatory subunit PTG.

\section{Results}

Structure of human GYS1 with a minimal interacting region of GYG1. Unlike C. elegans gsy-1 and yeast Gsy2p, producing large yields of recombinant soluble human GYS1 alone for structural studies has proven a challenge. However, co-expression with its binding partner, human GYG1, in an insect expression system has allowed for the isolation of this $\sim 0.5 \mathrm{mDa}$ complex as shown previously ${ }^{29,30}$. Using the same system, we co-expressed and purified the full-length GYS1:GYG1 ${ }^{\mathrm{FL}}$ complex (Extended Data Fig. 1b) but found it recalcitrant for crystallization. This was likely due to a combination of flexible regions along with heterogeneous phosphorylation and glucosylation of GYS1 and GYG1 respectively, as reported previously ${ }^{29,30}$ and determined by denaturing mass spectrometry (Extended Data Fig. 2a). As the complex is of sufficient size, cryo-EM was attempted but the GYS1:GYG1 ${ }^{\mathrm{FL}}$ complex was prone to aggregation and gave heterogenous particle sizes (Extended Data Fig. 1d).

Human GYG1 consists of an N-terminal catalytic domain, flexible linker, and a small C terminal GYS1-interacting domain (Fig. 1a). The crystal structure of full-length C. elegans gsy-1 in complex with the last 34 residues of gyg-1 demonstrated that this highly-conserved C-terminal region forms a helix-turn-helix motif sufficient for interaction with $\mathrm{GYS}^{28}$. In our attempts to improve the complex for crystallization, we designed bi-cistronic constructs encoding untagged human GYS1 (aa 1-737) and His 6-GST-tagged human GYG1 C-terminus (aa 264-350 or aa 294-350). Co-expression with GYG1 294-350 allowed for recovery of sufficient quantities of soluble GYS1 (Extended Data Fig. 1a). 
bioRxiv preprint doi: https://doi.org/10.1101/2021.11.12.468446; this version posted November 13, 2021. The copyright holder for this preprint (which was not certified by peer review) is the author/funder, who has granted bioRxiv a license to display the preprint in perpetuity. It is made available under aCC-BY 4.0 International license.

Structural Basis of Human GYS1 Regulation

This construct (GYS1:GYG1 ${ }^{\Delta \mathrm{CD}}$ ) is multiply phosphorylated as detected by intact mass spectrometry (Extended Data Fig. 2a). Using a coupled spectrophotometric assay, this truncated complex had similar GT activity to the wild-type GYS1:GYG1 ${ }^{\mathrm{FL}}$ complex, and for both complexes activity was stimulated by Glc6P (Extended Data Fig. 2b). Despite considerable effort no crystals were obtained of GYS1:GYG1 ${ }^{\triangle C D}$, however it showed improved behaviour in cryo-EM grids presenting less aggregation than GYS1:GYG1 ${ }^{\mathrm{FL}}$. Individual particles with a distinctive box-like shape were easily discernible and initial 2D classification resulted in classes representative of a tetrameric particle (Extended Data Fig. $1 \mathrm{~d}, \mathrm{e})$.

We determined a $3.0 \AA$ structure of the phosphorylated GYS1:GYG1 ${ }^{\Delta \mathrm{CD}}$ complex with $D 2$ symmetry applied (Fig. 1b, Extended Data Fig. 3). The cryo-EM map has a resolution range from 2.9 $\AA$ at the core to $3.9 \AA$ at the periphery of the complex, allowing for modelling of residues $13-289,293$ $629,637-645$ of GYS1 and residues 317-349 of GYG1. As expected, the complex adopts a rectangular box-shape with residues 317-349 of GYG1 at each corner of the GYS1 homo-tetramer (Fig. 1b, Extended Data Fig. 4a). Each GYS1 monomer consists of two Rossmann domains and a tetramerization domain, and interacts with GYG1 in a 1:1 ratio (Extended Data Fig. 4b). GYS1 assembles into a dimer of dimers with two major interfaces (Fig. 1b, Extended Data Fig. 4a): a tetrameric interface formed by tetramerization domains $(\mathrm{A} / \mathrm{D}, \mathrm{B} / \mathrm{C}$ interfaces $)$ and a dimeric/regulatory interface $(\mathrm{C} / \mathrm{D}, \mathrm{A} / \mathrm{B}$ interfaces $)$. The latter is contributed by the regulatory helix $\alpha 24$ from each subunit, harbouring conserved arginine clusters. In this state, each GYS1 active site, located at the cleft between the two Rossmann domains, is in a closed conformation due to additional inter-subunit contacts at a minor interface $(B / D, A / C)^{16,28}$. Here, helix $\alpha 2$ of Rossmann domain 1 contacts helix $\alpha 16$ of the tetramerization domain of the neighbouring subunit via a salt bridge between Glu 78 and Lys429 along with a hydrogen bond between Leu107 and Arg430 (Extended Data Fig. 4c).

The interactions of GYG1 with GYS1 are very similar to that found in the C. elegans crystal structure $^{28}$ (Fig. 1c, Extended Data Fig. 5b). GYG1 uses a helix $(\alpha \mathrm{A})$-turn-helix $(\alpha \mathrm{B})$ motif to interact with helices $\alpha 4, \alpha 9$, and $\alpha 10$ of hGYS1, with a combination of hydrogen bonds and hydrophobic interactions (Fig, 1c, Extended Data Fig. 5b). Looking at the hGYS1 region where hGYG1 interacts we observed a cysteine-rich pocket of residues Cys137, Cys189, and Cys251 near the last $\alpha$-helix of hGYG1 (Fig. 1d). The distances between Cys137 and Cys189 (3.39 $\AA$ ), and between Cys189 and Cys251 (4.18 $\AA$ ) are within disulphide-bonding distance. Lower threshold values of the cryo-EM density indeed suggest possible disulphide bond between Cys137 and Cys189 (Fig. 1d inset), however due to its ambiguity we modelled all three cysteine residues as reduced. Without GYG1 this cysteinerich pocket of GYS1 would be solvent-exposed, thus GYG1 may stabilise this region by preventing aberrant disulphide formation. The lack of this cysteine-rich pocket (Cys137, Cys189, Cys251) in yeast Gsy2p (replaced by Val126, Pro177, Ser240) and C. elegans GYS1 (replaced by Cys154, Leu207, Thr269) may explain the unique requirement of co-expressing GYG1 to stabilise GYS1 in human. 
bioRxiv preprint doi: https://doi.org/10.1101/2021.11.12.468446; this version posted November 13, 2021. The copyright holder for this preprint (which was not certified by peer review) is the author/funder, who has granted bioRxiv a license to display the preprint in perpetuity. It is made available under aCC-BY 4.0 International license.

Structural Basis of Human GYS1 Regulation

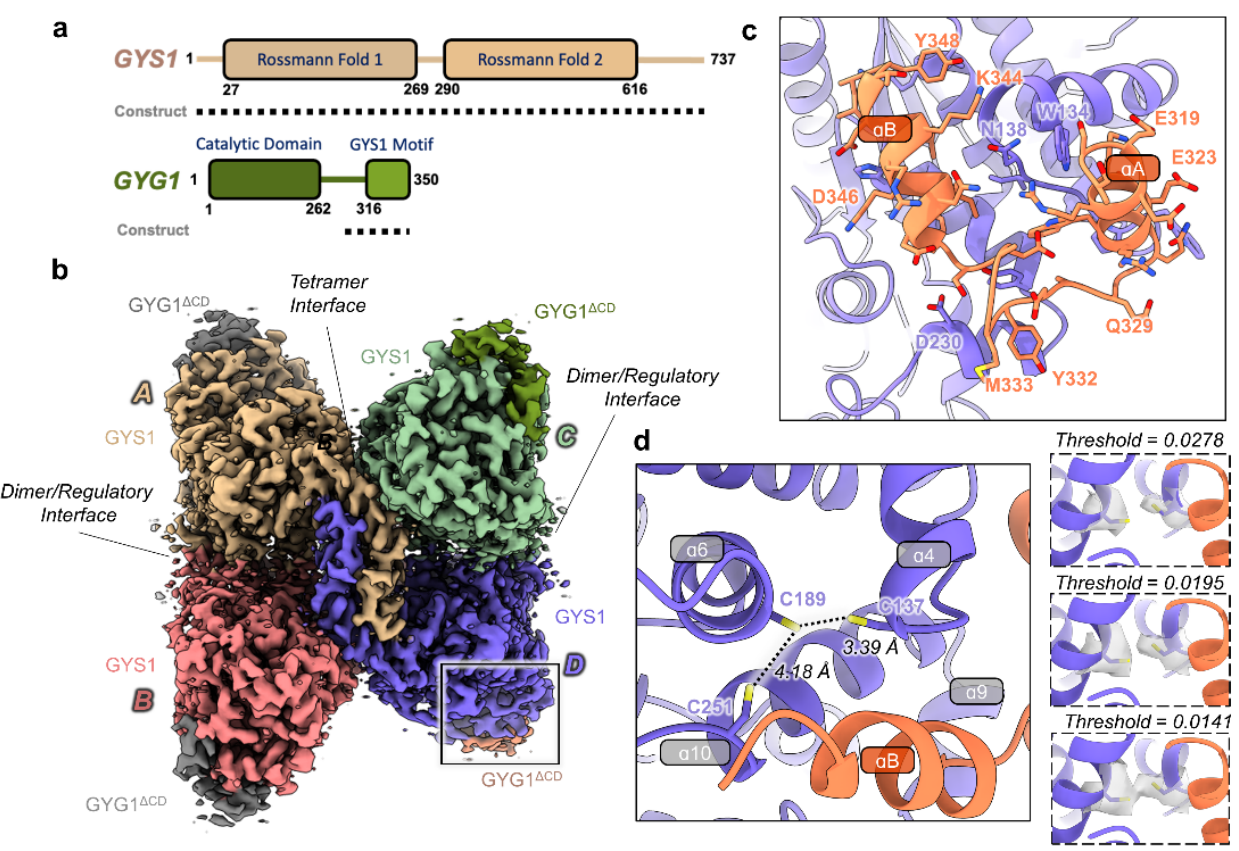

Fig. 1 Structure of the phosphorylated inhibited/T state GYS1:GYG1 ${ }^{\Delta C D}$ complex. a, Domain diagrams of human GYS1 and GYG1. Dotted lines represent the construct boundaries of the GYS1:GYG1 ${ }^{\triangle \mathrm{CD}}$ complex used in all cryo-EM experiments. b, Cryo-EM map of the tetrameric GYS1:GYG1 ${ }^{\triangle \mathrm{CD}}$ complex at $3.0 \AA$ resolution. Individual GYS1 and GYG1 subunits are colored separately. c, Enlarged view of the GYG1 region interacting with GYS1. GYS1 is colored purple and GYG1 is colored coral. d, Residues Cys137, Cys189, and Cys251 form a cysteine rich pocket on GYS1 at the interface with GYG1. Inset: Different contour levels for the cryo-EM density of Cys137 and Cys189 are shown.

The structural basis of phosphorylation sensing. As-purified GYS1 was highly phosphorylated (Extended Data Fig. 2a), which is representative of the inhibited/T state and supported by the lack of GT activity in the absence of Glc6P (Extended Data Fig. 2b). However, GYS1 in this state adopts a similar conformation with the C. elegans gsy- 1 and yeast Gsy2p basal/I state structures, with R.M.S.D. of $0.95 \AA$ and $0.93 \AA$ respectively (Extended Data Fig. 5a). In eukaryotic GYS, the N- and C-termini harbour several phosphorylation sites that mediate inhibition ${ }^{12,13}$ (Fig. 2a), and each phosphorylated site has been suggested to interact with specific conserved arginine residues present on a regulatory helix $\alpha 24^{16,28}$. In our $3.0 \AA$ map, density was present for modelling the $\mathrm{N}$ - and C-termini (Fig. 2b, Extended Data Fig. 6).

Both termini follow a trajectory different from that observed for the non-phosphorylated $C$. elegans gsy-1 basal/I state, and do not form any secondary structure (Extended Data Fig. 5c). In our inhibited/T state, the $\mathrm{N}$ - and $\mathrm{C}$ - termini from each subunit traverse from and towards the two regulatory helices $\alpha 24$ at the dimeric $(\mathrm{C} / \mathrm{D}, \mathrm{A} / \mathrm{B})$ interface, respectively. We modelled the $\mathrm{N}$-terminus, from residue Pro13 onwards. Despite no clear density present for phosphorylation sites 2 (Ser8) and 2a (Ser11), based on our structure they are positioned near the regulatory helix $\alpha 24$ of the subunit across the dimeric interface, and close to both Arg579 and Arg580, which could potentially sense the phosphorylation at these sites (Fig. 2b). The $\mathrm{N}$ - and C-termini from one subunit traverse in antiparallel fashion towards its own regulatory helix $\alpha 24$, and the helix $\alpha 24$ from the subunit across the dimeric interface (Fig. $2 b$ ). Strong density was apparent, in both $C 1$ and $D 2$ symmetry maps, between Arg588 and Arg591 of both GYS1 subunits at the dimeric interface (Fig, 2c, Extended Data Fig. 6b). We can trace and model a single phosphorylated site 3a (Ser641) (Fig. 2c), which is the first C-terminus phosphorylation site in the sequence (Fig. 2a). The density of this region was symmetric in both the $C 1$ and $D 2$ symmetry maps (Extended Data Fig. 6c) and likely represents an average of different conformations of the C-termini. However, aided by both the unfiltered and LAFTER denoised maps (Extended Data Fig. 6c), C-terminal residues Pro637-Val642 for one subunit and Pro637-Ser641 for the other across the dimeric interface 
bioRxiv preprint doi: https://doi.org/10.1101/2021.11.12.468446; this version posted November 13, 2021. The copyright holder for this preprint (which was not certified by peer review) is the author/funder, who has granted bioRxiv a license to display the preprint in perpetuity. It is made available under aCC-BY 4.0 International license.

Structural Basis of Human GYS1 Regulation

were modelled (Fig. 2c). This clearly shows that Arg588 and Arg591 from both subunits sense the phosphorylation from a single $3 \mathrm{a}$ site, at any time (Fig $2 \mathrm{c}$ ). This implies that the other C-terminus from the dimeric interface is excluded by steric occlusion, and both C-termini appear to traverse away from the main body of the enzyme as evidenced by the density of the map (Extended Data Fig. 6d) and fuzzy protrusions from this region as seen in 2D classes (Extended Data Fig. 1e). Altogether, our model of this inhibited state suggests that the non-symmetric interaction of a single phosphorylated site $3 \mathrm{a}$ at the dimeric $(\mathrm{C} / \mathrm{D}, \mathrm{A} / \mathrm{B})$ interfaces, combined with inter-subunit interactions of phosphorylated sites $2 / 2 \mathrm{a}$ across the interface, stabilise the hGYS1 enzyme in the inhibited state.

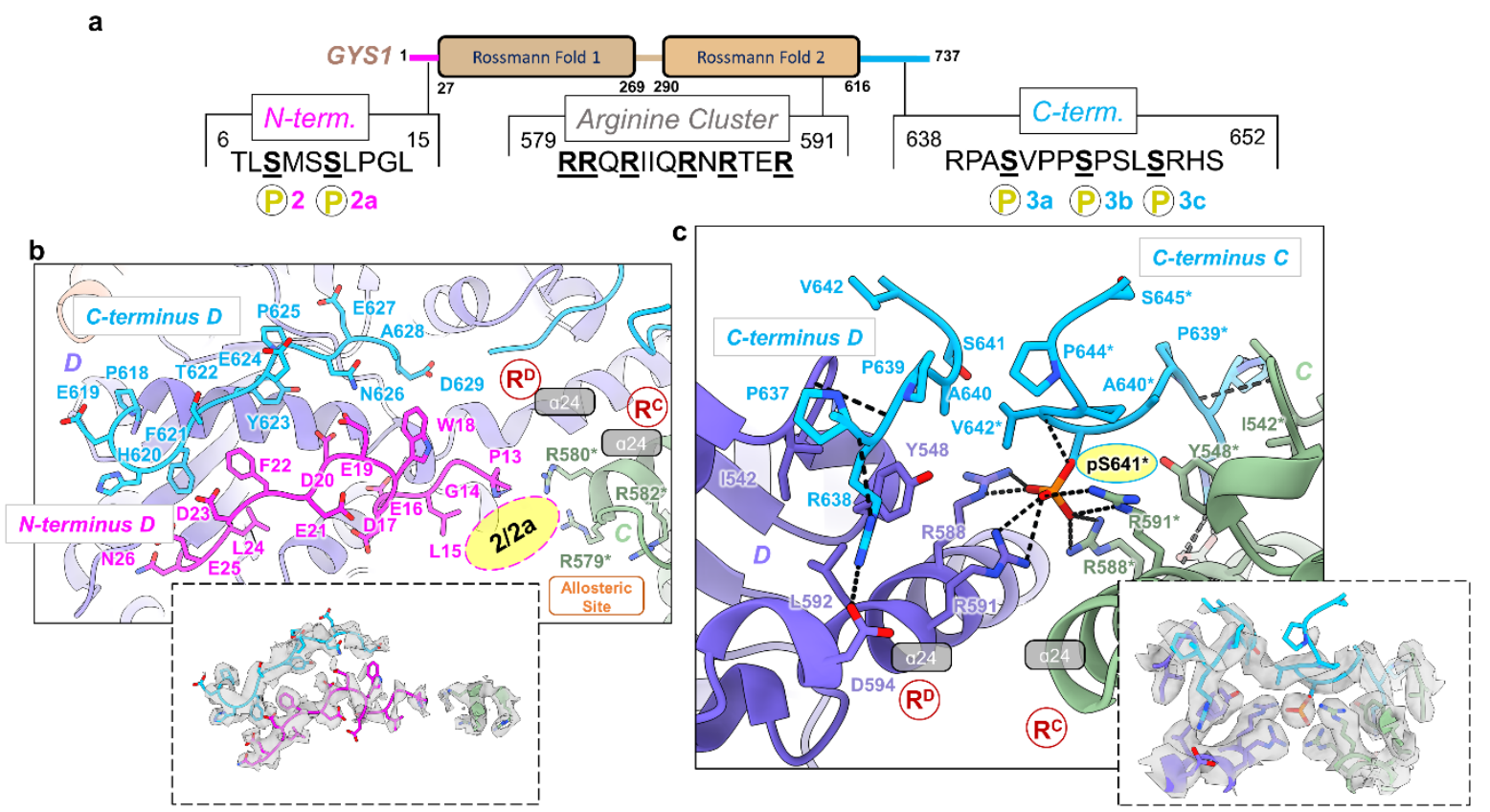

Fig. 2 | N- and C- termini of phosphorylated GYS1:GYG1 ${ }^{\triangle C D}$ complex in the inhibited/T state. a, Key sites of phosphorylation and arginine cluster of a GYS1 subunit. b, Model of the N- and C-termini from one subunit (D shown) pointing towards the allosteric sites and arginine clusters $\left(\mathrm{R}^{\mathrm{C}}, \mathrm{R}^{\mathrm{D}}\right.$ ) at the dimeric C/D interface. Inset shows EM density of both termini along with arginine residues from the neighboring subunit that would interact with phosphorylation sites 2 and 2a. c, Model of the C-termini residues 637-645 from two neighboring subunits (C, D shown) interacting with their arginine clusters at the dimeric $\mathrm{C} / \mathrm{D}$ interface. Inset shows EM density of both C-termini along with arginine clusters from both subunits interacting with a single site 3 a phosphorylation (pS641). Asterisk indicates residues from the neighboring subunit. Arginine clusters containing helices $\alpha 24$ are labelled. Putative location for phosphorylation sites 2 and 2 a are indicated by pink oval.

Allosteric activation by glucose-6-phosphate. To reveal GYS1 in the activated/R state, we determined a $3.7 \AA$ resolution structure in the presence of the allosteric activator Glc6P (Fig. 3a, Extended Data Fig. 7), and a $3.0 \AA$ resolution structure in the presence of both Glc6P and the glucose donor UDP-glc (Fig. 3b, Extended Data Fig. 8). Compared to the inhibited/T state, Glc6P induces large global structural changes in GYS1 that result in an outward rotation of $\sim 35^{\circ}$ of each subunit along the tetramer axis (Fig. $3 a)$. This removes inter-subunit contacts at the minor interface $(B / D, A / C)$ between the N-terminal Rossmann domain 1 of one subunit with the tetramerization domain of the neighbouring subunit (Extended Data Fig. 4c), freeing access to the active site between the Rossmann domains. When aligning one GYS1 subunit each from the inhibited/T and activated/R states, the tetramerization domain of the neighboring subunit (minor $\mathrm{B} / \mathrm{D}, \mathrm{A} / \mathrm{C}$ interface) moves by $\sim 18.6 \AA$ away with respect to Rossman domain 1 (Fig. 3a, Extended Data Fig. 9a). The increased flexibility of the N-terminal Rossman domain is quite evident in the EM map as this region is quite blurred and is of much lower resolution $(\sim 5.0 \AA$ resolution) in comparison to the enzyme's core ( $\sim 3.6 \AA$ resolution, Extended Data Fig. $7 \mathrm{~d})$. 
bioRxiv preprint doi: https://doi.org/10.1101/2021.11.12.468446; this version posted November 13, 2021. The copyright holder for this preprint (which was not certified by peer review) is the author/funder, who has granted bioRxiv a license to display the preprint in perpetuity. It is made available under aCC-BY 4.0 International license.

Structural Basis of Human GYS1 Regulation

Glc6P binds identically to both R state structures, so we describe its binding mode based on the higher resolution structure bound with Glc6P and UDP-glc (Fig. 3c). Three arginines from the regulatory helix a24 (Arg579, Arg582, and Arg586), along with Lys301 and His501, interact with the phosphate moiety of Glc6P. The glucose moiety is recognised by His287, Gln294, and Arg586 from its own subunit (i.e. in cis), along with the now ordered residues (His291, Glu292) at the end of helix $\alpha 13$ from the neighbouring subunit across the dimeric interface (i.e. in trans). The binding mode of Glc6P and the disordered-to-ordered transition of residues 290-292 are conserved in the Glc6P bound yeast gsy $2 p$ crystal structure ${ }^{16}$. Ordering of this region is essential for the structural transition from the basal or inhibited state to the activated state (next section).

The activated/R state bound with UDP-glc is in a similar conformation to the activated/R state without UDP-glc (R.M.S.D. of $0.71 \AA$ ) except for a $\sim 20^{\circ}$ rotation of the Rossmann domain 1 relative to Rossmann domain 2, which closes the active site cleft (Fig. 3b, d). We observed density at the sugar donor site which fits better as individual UDP and glucose moieties, suggesting that UDP-glc was hydrolysed (Fig. 3e). This is similar to an activated structure of yeast gsy2p incubated with UDP-glc, in which one subunit has UDP and glucose bound ${ }^{17}$. Structural alignment shows that the Rossmann domain closure is identical to that of yeast gsy2p with (R.M.S.D. of $0.91 \AA$ ) and the UDP-glc binding residues are highly conserved (data not shown). In our structure, the uridine moiety of UDP is sandwiched between Ile367, Phe481, and Tyr493, also forming a hydrogen bond with Lys19 (Fig. 3e). The backbone of Gly41 and the sidechain of Glu518 interacts with the ribose moiety, while Arg331 and Lys337 disperse the charge of the diphosphate moiety. The hydrolysed glucose molecule forms multiple hydrogen bonds with the sidechains of Arg211, Arg311, Glu510, and Tyr514 along with the backbones of His205, Trp512, and Gly513. Additionally, Ala206 and Pro511 form hydrophobic interactions with the sugar (Fig. 3e).

This UDP-glc bound activated/R state is predicted to be the catalytic competent state poised for binding the glucose chain substrate ${ }^{26,31}$, and is different from the inhibited/T state as interactions of helix $\alpha 2$ with the central tetramerization domain at the minor interface $(\mathrm{B} / \mathrm{D}, \mathrm{A} / \mathrm{C})$ are still broken (Extended Data Fig. 9a). The features of the N-terminal Rossmann domain 1 are also highly blurred (Extended Data Fig. 8d) suggestive of increased flexibility. To gain further insight into substrate binding and catalysis, we aligned one subunit of each of our states with the structure of $E$. coli glycogen synthase (GS) incubated with maltohexaose resulting in three glucose moieties bound to the active site $(\mathrm{PDB} 3 \mathrm{CX} 4)^{31}$. E. coli GS is in a closed conformation with respect to the active site and aligns with a R.M.S.D. of $1.09 \AA$ and $1.19 \AA$ against our hGYS1 inhibited and activated states respectively (Extended Data Fig. 9b). We find the glucose moieties occupy the +1 to +3 sites while the hydrolyzed glucose in our EM map is in the +0 site (Extended Data Fig. 9b). This predicted binding site of the glucan has conserved residues between E. coli GS and human GYS1 (Extended Data Fig. 9b) and suggests that the initial growing glucose chain is fed into and then out of the GYS1 active site through a cleft formed by helices $\alpha 1, \alpha 5, \alpha 6, \alpha 7$, and $\alpha 9$ of Rossmann domain 1 (Extended Data Fig. 9b, d). This pocket is not closed in the inhibited/T state and may explain the large increase in affinity for UDP-glc ${ }^{32}$ and glycogen when hGYS1 is in the activated/R state ${ }^{33}$ (Extended Data Fig. 9c). 
bioRxiv preprint doi: https://doi.org/10.1101/2021.11.12.468446; this version posted November 13, 2021. The copyright holder for this preprint (which was not certified by peer review) is the author/funder, who has granted bioRxiv a license to display the preprint in perpetuity. It is made available under aCC-BY 4.0 International license.

Structural Basis of Human GYS1 Regulation

a

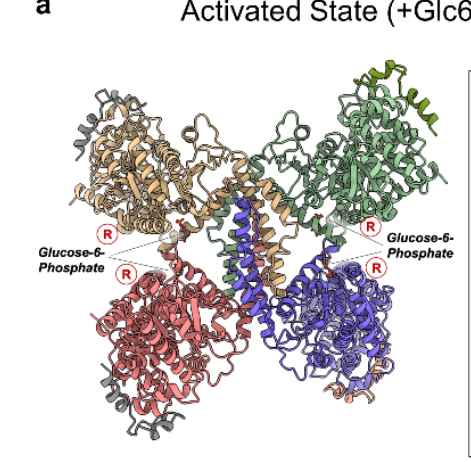

C

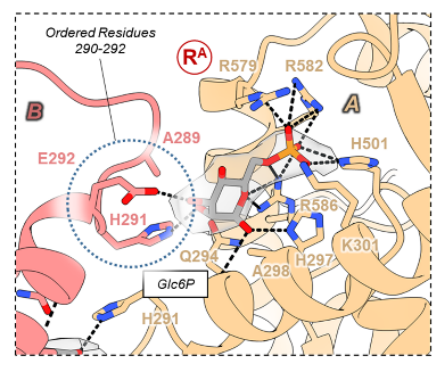

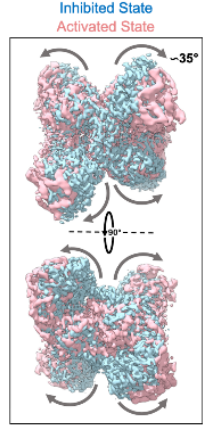

d b

Activated State Plus Substrate (+GIc6P, UDP, \& Glc)

Fig. 3 Activated structures of the phosphorylated R state GYS1:GYG1 ${ }^{\Delta C D}$ complex without and with substrate. a, Structure of the Glc6P bound activated (R) state determined from a $3.7 \AA$ map. Inset shows the global conformational changes resulting from Glc6P activation in comparison to the inhibited (T) state. b, Structure of the activated (R) state bound to Glc6P, UDP, and glucose determined from a $3.0 \AA$ map. Inset shows the global conformational changes resulting from substrate binding in the activated state. Regulatory/arginine cluster containing helices $(\alpha 24)$ are labelled R. c, Cis and trans interactions with the Glc6P activator in the $\mathrm{R}$ state determined from the higher resolution substrate bound map. Interactions with glucose-6-phosphate in the lower resolution map without substrate are the same. Cryo-EM density for Glc6P is shown. d, Conformational changes of Rossmann domain 1 in relation to Rossmann domain 2 due to UDP and glucose binding in the R state. e, Interactions with UDP and glucose in the R state. Cryo-EM densities for both ligands are shown.

Phosphorylation attenuates allosteric activation by glucose-6-phosphate. During the processing of the GYS1:GYG1 ${ }^{\Delta \mathrm{CD}}+\mathrm{Glc} 6 \mathrm{P}$ dataset, one 3D class appeared structurally similar to the inhibited/T state. This class was refined to 4.0 A resolution with D2 symmetry applied (Extended Data Fig.10). While similar to our inhibited/T state map, where phosphorylated Ser641 of the C-terminus interacts with the arginine clusters, density for Glc6P in the allosteric site was apparent for this structure (Fig. 4a). Unlike the activated/R state, Glc6P in this structure does not interact with subunits in trans (across the dimeric interface) because residues 290-292, which interact with the glucose moiety in trans in the activated/R state, remain disordered. In this 'inhibited-like' state, all interactions involve the phosphate group and are identical to the activated states except for Arg586 which is not in a productive conformation to interact with both the glucose and phosphate moieties of Glc6P (Fig. 4c).

With regards to allosteric activation, this 'inhibited-like' state potentially exists in dynamic equilibrium with the activated state. The binding of Glc6P is well known to overcome the inhibitory effects of phosphorylation, however reported $\mathrm{k}_{\mathrm{a}}$ values of Glc6P for phosphorylated GYS1 vary between 0.33-1.8 $\mathrm{mM}$ from insect cell-expressed GYS1 ${ }^{29,30}$ and between $0.8-1.9 \mathrm{mM}$ for rabbit $\mathrm{GYS1}^{34}$. Dephosphorylation significantly reduces the amount of Glc6P to half maximally activate the enzyme $\left(\mathrm{A}_{50}\right)$ within a range of $\sim 3, \sim 10$, or $\sim 100$ fold $^{35}$. These diverse values likely reflect phosphorylation heterogeneity of each GYS1 sample, and suggest an interplay between phosphorylation and Glc6P activation. To explore how this interplay impacts the complex at the molecular level, we applied the thermal shift assay and titrated Glc6P against our three complexes (GYS1:GYG1 ${ }^{\mathrm{FL}}$, GYS1:GYG1 ${ }^{\triangle \mathrm{CD}}$,

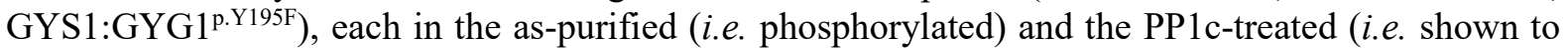
partially dephosphorylate the protein, particularly at key sites ${ }^{19}$ ) forms (Extended Data Fig. 2a). For all three complexes, dephosphorylation significantly reduced thermal stability by $\sim 6^{\circ} \mathrm{C}$ (Fig. 4 b, Extended 
bioRxiv preprint doi: https://doi.org/10.1101/2021.11.12.468446; this version posted November 13, 2021. The copyright holder for this preprint (which was not certified by peer review) is the author/funder, who has granted bioRxiv a license to display the preprint in perpetuity. It is made available under aCC-BY 4.0 International license.

Structural Basis of Human GYS1 Regulation

Data Fig. 11), suggesting that the phosphorylated inhibited/T state is more stable than the dephosphorylated basal/I state. This is possibly due to the loss of stabilising interactions of phosphorylated 2, 2a, and 3a sites with the arginine clusters. Significantly for all three constructs, Glc6P had no to little stabilizing effect towards phosphorylated complexes, whereas each dephosphorylated complex was readily stabilized by Glc6P with a maximal increase in melting temperature of $\sim 8-12^{\circ} \mathrm{C}$ (Fig. 4b, Extended Data Fig. 11). The apparent $\mathrm{AC}_{50}$ (concentration of ligand to reach half maximal melting temperature) for each dephosphorylated construct was $1.47 \mathrm{mM}\left(\mathrm{GYS} 1: \mathrm{GYG1}{ }^{\mathrm{FL}}\right), 1.31 \mathrm{mM}$ (GYS1:GYG1 $\left.{ }^{\triangle C D}\right)$, and $0.84 \mathrm{mM}\left(\mathrm{GYS1}: \mathrm{GYG}^{\mathrm{p} . \mathrm{Y} 195 \mathrm{~F}}\right)$. These values are lower than the reported $\mathrm{k}_{\mathrm{a}}$ values for dephosphorylated GYS1, likely due to differences in the remaining phosphorylation of the samples and/or pleiotropic effects from substrates ${ }^{35}$.

Furthermore, we compared the orientation of regulatory helices $\alpha 24$ among our four structures (Fig. 4c). From these, the ordering of residues 290-292 at the end of helix $\alpha 13$ (which interact with Glc6P in trans across the dimeric interface) appears to be the driver of conformational change from the inhibited/T to activated/R states. The ordering of these residues is associated with movement of helix $\alpha 13$ towards the regulatory helix $\alpha 24$ across the dimeric interface, positioning the hydrophobic Met290 (from $\alpha 13$ ) to interact with Ile583 and Ile584 (from $\alpha 24$ ). This drives apart the regulatory helices across the dimeric interface, distancing them from $8.1 \AA$ to $13.6 \AA$ and abolishes the ionic interactions of Arg588 and Arg591 from both subunits with the single phosphorylated Ser641. This replacement of ionic with hydrophobic interactions allows for greater flexibility between each subunit, as this distance increases further to $14.0 \AA$ when the donor substrate is present (Fig. 4c).

To visualize this better, we applied $3 \mathrm{D}$ variability analysis to show that the activated/R states are far more flexible than the inhibited/T states (Supplementary Videos 1-5). In both the activated/R states, the Rossmann domain 1 flexes onto Rossmann domain 2. This flexing movement is even more pronounced when UDP and glucose are bound to the active site. No such Rossmann domain closure is apparent in both inhibited/T states. However, 3D variability analysis for the Glc6P bound inhibited-like state showed a unique movement not observed in the inhibited state without Glc6P. This movement appears as a $2.0 \AA$ expansion of the complex from the tetrameric interface (Supplementary Video 1, Extended Data Fig. 12a) and by flexibly fitting our inhibited state model, we observe that helix $\alpha 13$ moves towards the regulatory helices (Extended Data Fig. 12b, c). Such movement suggests that this inhibited-like state is primed to change into the activated state either by changes in dynamic equilibrium, binding of substrate and/or dephosphorylation by PP1. As we only incubated with $5 \mathrm{mM}$ Glc6P for the phosphorylated GYS1:GYG1 ${ }^{\Delta C D}$ EM samples, these findings coupled with our thermal shift results suggest that the conformational change to the activated state is attenuated by the phosphorylation of site $3 \mathrm{a}$ and possibly $2 / 2 \mathrm{a}$. 
bioRxiv preprint doi: https://doi.org/10.1101/2021.11.12.468446; this version posted November 13, 2021. The copyright holder for this preprint (which was not certified by peer review) is the author/funder, who has granted bioRxiv a license to display the preprint in perpetuity. It is made available under aCC-BY 4.0 International license.

Structural Basis of Human GYS1 Regulation

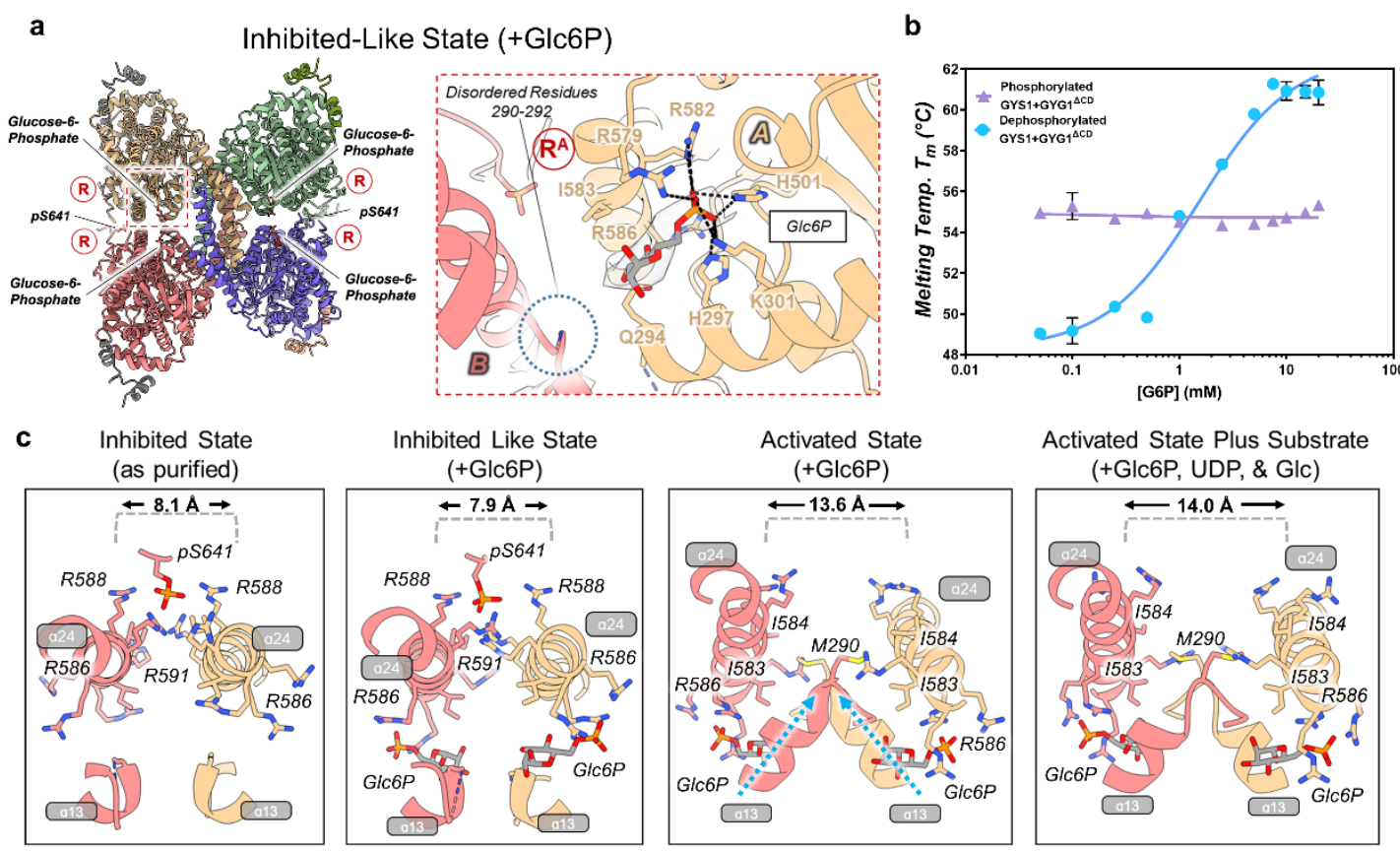

Fig. 4 | Phosphorylation hinders transition into the activated/R state as shown by the phosphorylated inhibited/T state bound to glucose-6-phosphate. a, Overall model of the phosphorylated T state bound to Glc6P and the interactions with this activator. Inset shows cryo-EM density for glucose-6-phosphate. Regulatory/arginine cluster containing helices ( $\alpha 24)$ are labelled R. b, Thermal shift assay of phosphorylated (as purified) versus dephosphorylated (PP1 treated) GYS1:GYG1 ${ }^{\Delta C D}$ complex in the presence of increasing concentrations of glucose-6-phosphate. Median melting temperatures and standard deviations are shown ( $n=4$ technical repeats). $\mathbf{c}$, $\mathrm{R}$ helix interactions and conformational changes as seen in our cryo-EM structures. Key residues are labelled. Distances between the R helices ( $\alpha 24)$ were determined as the distance between the $\mathrm{C} \alpha$ of the Asn587 residues.

Associated glycogen is the main driver of PTG recruitment to the GYS1:GYG1 complex. PP1 is the only phosphatase known that dephosphorylates GYS1 in vivo with assistance from a glycogentargeting regulatory protein, such as PPP1R3C/PTG, which has been suggested to form a direct interaction with GYS ${ }^{19}$. Attempts to express full-length human PTG were not successful; we instead obtained soluble protein with a construct encompassing residues Leu134-Val259. This construct contains the carbohydrate binding module 21 (CBM21) domain (PTG(CBM21), residues 149-257) in which the predicted glycogen-binding motif VKNVSFEKKV (residues 175-184) and GYS-binding motif WDNNDGQNYRI (residues 246-256) are present.

We used affinity pull-down to evaluate the binding of PTG(CBM21) to complexes of GYS1 and GYG1 (Fig. 5). His-tagged PTG(CBM21) pulls down only GYS1:GYG1 ${ }^{\mathrm{FL}}$ where GYG1 is attached with glucose chain (glucosylated), at a level above background, but does not pull down GYS1:GYG1 ${ }^{\triangle C D}$ or GYS1:GYG1 ${ }^{\text {p.Y195F }}$ complexes where GYG1 is not glucosylated (Fig. 5a). This result agrees with analysis by blue-native PAGE (Fig. 5c), suggesting that PTG(CBM21) is recruited to GYS1 by the GYG1-associated glycogen. To confirm a direct interaction between PTG and the GYG1 glucose chain, we repeated the PTG pull-down with the catalytic domain alone from GYG1 wild-type (glucosylated) and GYG1 $1^{\text {p.Y195F }}$ (non-glucosylated), without GYS1. His-tagged PTG(CBM21) pulls down only GYG1 with glucosylation at a level above background, but not the non-glucosylated GYG1 ${ }^{\text {p.Y195F }}$ (Fig. 5b). Lastly, the polysaccharide binding ability of the PTG(CBM21) was studied by thermal shift assay. Only glycogen, debranched glycogen, maltotetraose, and maltoheptaose resulted in increased stability of PTG(CBM21) (Fig. 5d). Overall, these results suggest that associated glycogen of GYS1 is the major binding site of PTG and any direct interactions with GYS1 are potentially quite weak, outside of the domain boundaries of the CBM21, or only form in the presence of PP1. 
a
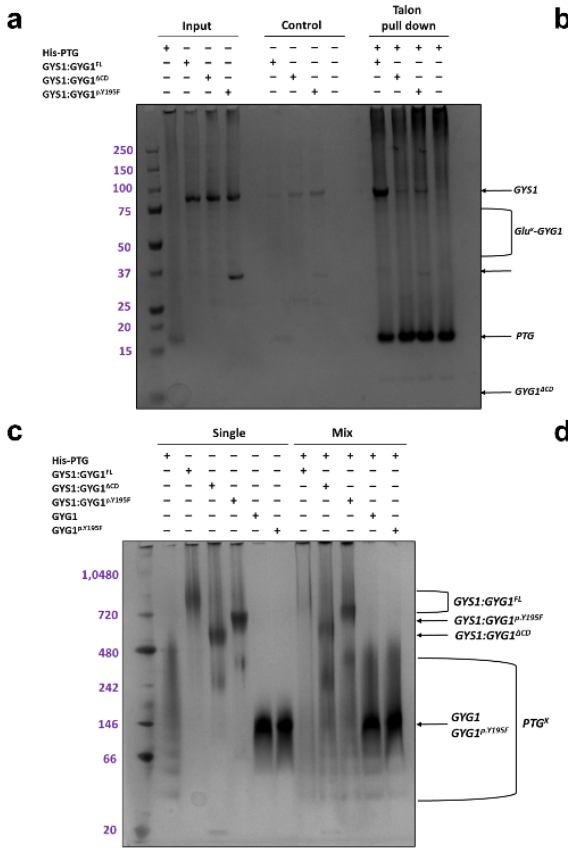

b

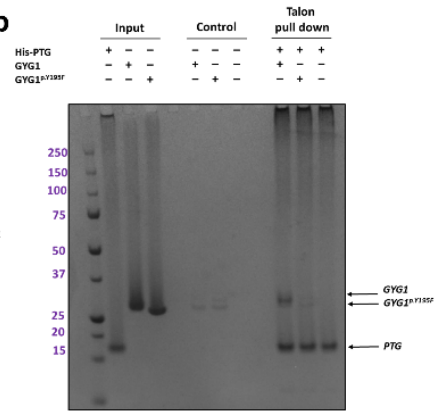

d

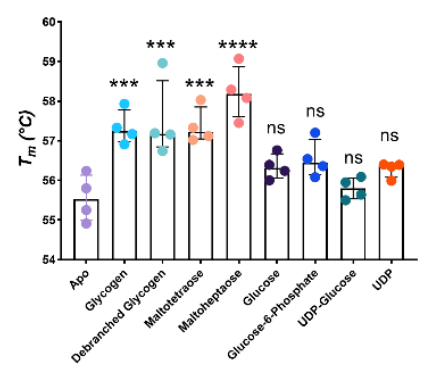

Fig. 5 | The CBM21 domain of PTG binds to the GYS1:GYG1 complex via the associated glucose chain. a, PTG(CBM21) was incubated with GYS1:GYG1 $1^{\mathrm{FL}}, \mathrm{GYS1}: \mathrm{GYG} 1^{\mathrm{p} . \mathrm{Y} 195 \mathrm{~F}}$, or GYS1:GYG1 ${ }^{\mathrm{CCD}}$. The ability of PTG to bind GYS1:GYG1 complexes was assessed by affinity pull-down, followed by SDS-PAGE ( $n=4$ technical repeats). b, PTG(CBM21) was incubated with GYG1, or GYG1 ${ }^{\text {p.Y195F }}$ catalytic domain constructs, passed onto affinity resin and analysed by SDS-PAGE $(n=4)$. GYG1 catalytic domain exists as a mixture of glucosylated states and runs at a higher apparent MW in SDSPAGE than GYG1 ${ }^{\text {p.Y } 195 F}$ which is non-glucosylated. c, Blue native PAGE shift of PTG(CBM21) incubated with GYS1:GYG1 ${ }^{\mathrm{FL}}$, GYS1:GYG1 $1^{\mathrm{p} . \mathrm{Y} 195 \mathrm{~F}}$, GYS1:GYG1 ${ }^{\Delta \mathrm{CD}}, \mathrm{GYG1}$ alone, or GYG1. ${ }^{\text {p.Y195F }}$ alone $(n=3)$. Complex formation between PTG(CBM21) and GYS1:GYG1 ${ }^{\mathrm{FL}}$ was inferred from the disappearance of bands compared to other reaction lanes. CBM21 appears as oligomers but behaves as a monomer with some dimer in solution (data not shown) $\mathbf{d}$, Thermal shift analysis of PTG(CBM21) in the presence of various sugars and ligands ( $n=4$ technical repeats). Significance was determined by two-tailed unpaired t test. ${ }^{* * *} \mathrm{p}<0.001 ;{ }^{* * * *} \mathrm{p}<0.0001$, ns: not significant.

\section{Discussion}

Glycogen synthase is a metabolic enzyme underpinning the classic paradigms of protein allostery and phosphorylation-dependent regulation. Despite the well-characterised enzyme kinetics, and the discovery nearly a decade ago that recombinant GYS1 can be co-expressed with GYG1, until now structural information for human GYS1 has remained elusive. Taking advantage of a minimal GYG1 interacting polypeptide that introduces less disorder to the complex with GYS1, and the capability of cryo-EM to classify subtle protein conformational features, we have determined the structure of phosphorylated human GYS1 under several inhibited and activated states, allowing us to chart its trajectory between phosphorylation mediated inhibition and allosteric activation.

Our inhibited state structures have unravelled the roles of phosphorylated $\mathrm{N}$ - and C-termini as a molecular "straitjacket", reducing the flexibility of the GYS1 tetramer and hindering the Glc6Pmediated conformational change to the activated state. Specifically phosphorylated site $3 \mathrm{a}$, and potentially also sites $2 / 2 \mathrm{a}$, are poised to interact with conserved arginine clusters at the dimeric interface, confirming their significance relative to other sites ${ }^{35}$. Sites 2/2a could interact with Arg579 and Arg580 in trans (subunit across the dimer interface). Unexpectedly we found that one single phosphorylation at site 3a interacts with Arg588 and Arg591 from both subunits at the dimeric interface (i.e. in both cis and trans). The essentiality of Arg579, Arg580, Arg588 and Arg591 for phosphorylation-dependent inhibition is supported by mutagenesis of equivalent residues in yeast gsy $2 \mathrm{p}^{16}$ and mouse GYS $1^{35-37}$. This is further underscored by reciprocal mutagenesis of sites $2 / 2 \mathrm{a}$ and $3 \mathrm{a}$ in rabbit GYS1 that ablated 
bioRxiv preprint doi: https://doi.org/10.1101/2021.11.12.468446; this version posted November 13, 2021. The copyright holder for this preprint (which was not certified by peer review) is the author/funder, who has granted bioRxiv a license to display the preprint in perpetuity. It is made available under aCC-BY 4.0 International license.

Structural Basis of Human GYS1 Regulation

inhibition by phosphorylation ${ }^{12,38}$ and/or improved sensitivity towards Glc6P activation ${ }^{39}$. The relative contributions of site $2 / 2 \mathrm{a}$ and site 3 in inducing phosphorylation-dependent inhibition remains unclear, and translating biochemical findings from yeast, mouse and rabbit orthologues to understanding the human enzyme may also be hindered by the variation in their $\mathrm{N}$-terminus lengths and sequences ${ }^{16,38,39}$.

The Glc6P binding site, involving Arg579, Arg582, and Arg586 of the arginine cluster, is highly conserved between yeast and human ${ }^{16}$. Particularly, the importance of Arg582 and Arg586 is confirmed by their substitution in rabbit and yeast GYS which abolished Glc6P activation ${ }^{16,35-37}$. The Glc6P induced conformational change is also conserved in yeast gsy $2 \mathrm{p}^{16}$, and our four human structures provide further clarity, showing that the ordering of residues Met290-Glu292 to interact with Glc6P in trans across the dimer interface drives the conformational change. This positions Met290 in-between the two regulatory helices $\alpha 24$ at the dimer interface, driving them apart with steric hinderance against Ile583 and Ile584 of the trans subunit. Therefore, Glc6P activation replaces the ionic interaction of phosphorylation with a hydrophobic interaction, allowing for greater flexibility between subunits and between the Rossmann domains from a single subunit that increase active site access. The equivalent residues of Met290, Ile583 and Ile584 in yeast (Phe299, Ile584, Asn585) and C. elegans (Leu308, Ile604, Ile605) suggest a shared mechanism for allosteric activation of glycogen synthase as a homotetramer.

Dephosphorylation of GYS1 by PP1 also relieves inhibition of GYS1 by removing the phosphorylation at sites $2 / 2 \mathrm{a}$ and $3 \mathrm{a}$ thus releasing the "straitjacket" effects of the $\mathrm{N}$ - and Ctermini ${ }^{29,30,35}$. PP1 is recruited to its substrate proteins by different regulatory subunits, of which seven are known to recruit it to glycogen ${ }^{40}$. Among them, PTG is ubiquitously expressed ${ }^{41}$ and considered a therapeutic target for GSDs ${ }^{22}$. All known glycogen-recruiting regulatory subunits differ in length, but share a PP1 binding motif and a CBM21 domain ${ }^{21}$. The latter contains two putative binding sites ${ }^{20}$, namely site II corresponding to a glycogen-binding motif $V x N x x F E K x V^{19-21}$, and site I WxNxGxNYx(I/L) suggested to be a GYS binding motif by work on the CBM21 domain of musclespecific PPP1R3A (65.7\% sequence similarity with PTG) ${ }^{19,42}$ (Extended Data Fig. 13). Our findings that PTG(CBM21) does not interact directly with GYS1 or GYG1 contrasts a recent study involving PPP1R3A and full-length GYS1:GYG1 complex, which does not account for GYG1 self-glucosylation within the context of the complex ${ }^{29}$. Our findings suggest rather that PTG (and possibly other PP1 regulatory subunits) recruits PP1 to GYS1 via the GYG1-attached glucose chain. With multiple surface sites in addition to the active site of GYS1 for glycogen contacts ${ }^{15}$, the PTG-glycogen interaction therefore provides for GYS1 processivity, by facilitating PP1 recruitment to flexibly dephosphorylate ${ }^{43}$ the many sites on the $\mathrm{N}$ - and C- termini of GYS1. It is however possible that a GYS1 binding site is formed in the context of full-length PTG or in complex with PP1 and therefore further investigation is needed (Extended Data Fig. 12).

Together with interaction studies of the PP1 regulatory subunit PTG, our structural snapshots of GYS1 reveal a model of its regulation by both Glc6P and phosphorylation, explaining how their interplay alters the equilibrium of the various GYS1 states, further elaborating the lock-and-key hypothesis of these two effectors (Fig 6) ${ }^{16,35}$. This dynamic system likely allows for fine tuning of glycogen formation in response to upstream messengers such as insulin ${ }^{14}$. Furthermore, our structures provide novel opportunities in rational drug design of GYS1 inhibitors for treatment of GSDs. The validity of GYS1 as a target is supported by proof-of-concept GYSI knockout in cell and animal models $\mathrm{s}^{43,44}$, and a safety profile is underscored by healthy individuals with reduced GYS1 enzyme activity ${ }^{45,46}$. Preventing dephosphorylation by targeting PTG and targeting the Glc6P allosteric site appear to be ideal starting points for inhibitor design. Indeed ATP has been suggested to be a competitive inhibitor of Glc6P and may trap GYS1 in an inhibited state ${ }^{35}$. Overall, our structural work elucidates decades of studies on the arginine clusters, key phosphorylation sites, and the conformational flexibility of GYS1. 
bioRxiv preprint doi: https://doi.org/10.1101/2021.11.12.468446; this version posted November 13, 2021. The copyright holder for this preprint (which was not certified by peer review) is the author/funder, who has granted bioRxiv a license to display the preprint in perpetuity. It is made available under aCC-BY 4.0 International license.

Structural Basis of Human GYS1 Regulation

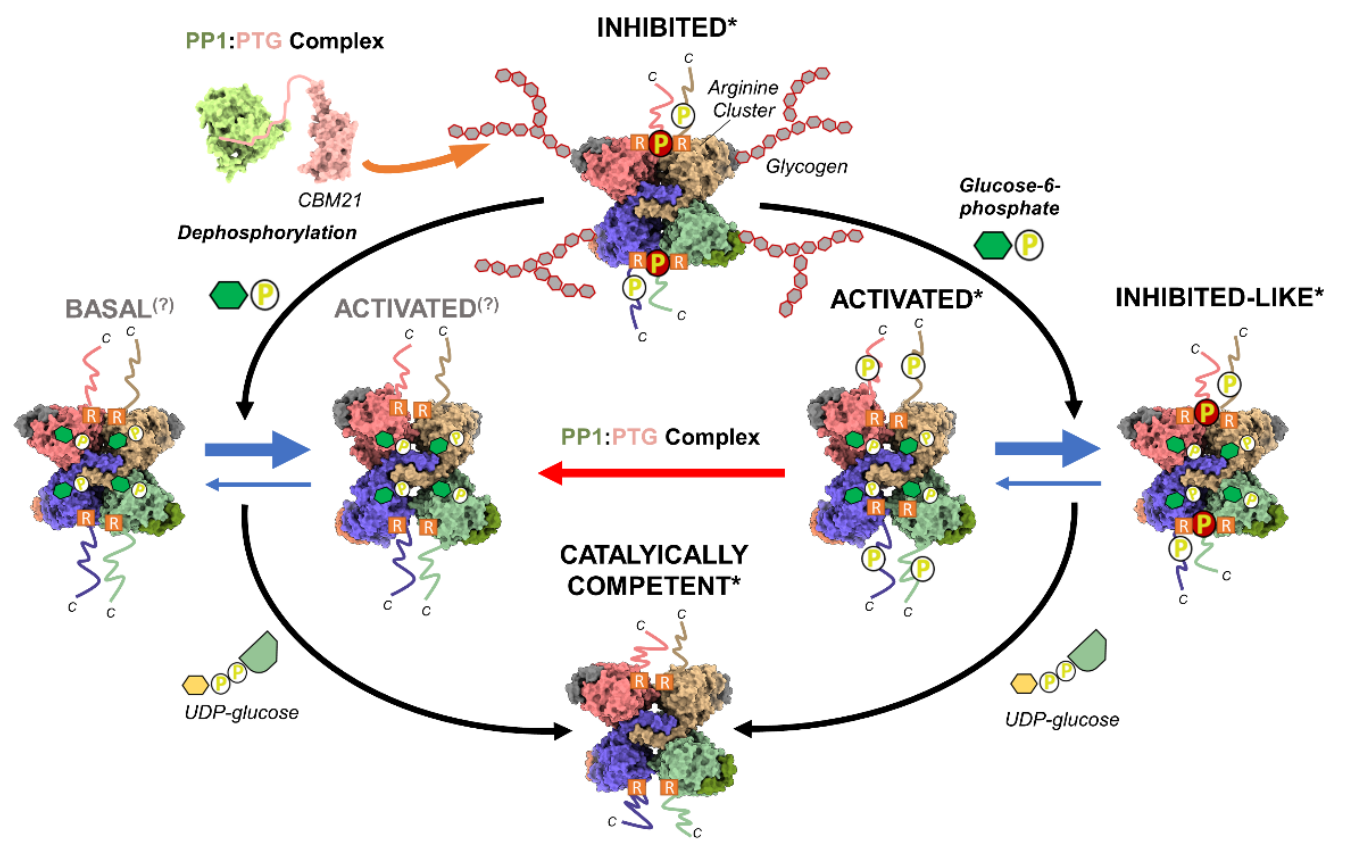

Fig. 6 | Proposed model of phosphorylation and glucose-6-phosphate regulation of hGYS1 activity. Only the C-termini and 3 a phosphorylation site are shown for simplicity. Additionally, the associated glycogen is only shown for the inhibited state, though it is present in all other states. Structures with an asterisk are experimentally determined. Structures with a question mark are theoretical. Our model based on the structural data proposes that the inhibited/T state is catalytically inactive because the phosphorylated $\mathrm{N}$ - and $\mathrm{C}$ - termini bind to a subunit interface. This locking interaction reduces GYS1 flexibility and prevents active site closure by the two Rossmann domains. Glc6P binding to the allosteric site overcomes these inhibitory effects to promote a conformational change to the activated/R state. However, this activated/R state is in a dynamic equilibrium with an inhibited-like state, due to the competition between the locking interactions of phosphorylated termini at the subunit interface and the conformational change due to Glc6P binding. The inhibition of phosphorylation can also be relieved by the concerted actions of the PP1:PTG complex that binds to the associated glycogen and dephosphorylates the GYS1 N- and C-termini, resulting in the basal/I state. This intermediate state is more susceptible to the allosteric effects of Glc6P binding, shifting the dynamic equilibrium more towards the activated state. In the activated state binding of the substrate UDP-glc promotes the closure of the cleft between the two Rossman domains resulting in a catalytically competent state for extending the associated glycogen chain. 
bioRxiv preprint doi: https://doi.org/10.1101/2021.11.12.468446; this version posted November 13, 2021. The copyright holder for this preprint (which was not certified by peer review) is the author/funder, who has granted bioRxiv a license to display the preprint in perpetuity. It is made available under aCC-BY 4.0 International license.

Structural Basis of Human GYS1 Regulation

\section{Table 1}

Cryo-EM data collection, refinement, and validation statistics

\begin{tabular}{|c|c|c|c|c|}
\hline & $\begin{array}{c}\text { GYS1:GYG1 } \\
\text { inhibited state } \\
\text { (EMDB-13743, } \\
\text { PDB-7Q0B) }\end{array}$ & $\begin{array}{c}\text { GYS1:GYG1 }{ }^{\Delta C D}+\text { Glc6P } \\
\text { inhibited like-state } \\
\text { (EMDB-13751, } \\
\text { PDB-7Q0S) }\end{array}$ & $\begin{array}{c}\text { GYS1:GYG1 }{ }^{\Delta C D}+\text { Glc6P } \\
\text { activated state } \\
\text { (EMDB-13752, } \\
\text { PDB-7Q12) }\end{array}$ & $\begin{array}{c}\text { GYS1:GYG1 }^{\text {GCD}^{\mathrm{CD}}+\text { Glc6P }} \\
\text { +UDP-glc } \\
\text { activated state } \\
\text { (EMDB-13753, } \\
\text { PDB-7Q13) } \\
\end{array}$ \\
\hline \multicolumn{5}{|l|}{ Data collection and Processing } \\
\hline Magnification & 81,000 & 81,000 & & 81,000 \\
\hline Voltage (kV) & 300 & 300 & & 300 \\
\hline Detector & K3 (Super-Resolution) & K3 (Super-Resolution) & & K3 (Super-Resolution) \\
\hline Exposure $\left(\mathrm{e}^{-} / \AA^{2}\right)$ & 55.0 & 55.0 & & 50.00 \\
\hline Dose rate (e- $/ \AA^{2} /$ frame $)$ & 1.22 & 1.22 & & 1.00 \\
\hline Pixel size $(\AA ̊)$ & 1.086 & 1.086 & & 1.06 \\
\hline Defocus range $(\mu \mathrm{m})$ & -0.8 to -2.3 & -0.8 to -2.3 & & -0.8 to -2.3 \\
\hline Initial particles (no.) & $1,908,826$ & $4,391,867$ & & $10,011,868$ \\
\hline Final particles (no.) & 113,271 & 40,062 & 15,379 & 35,604 \\
\hline Symmetry imposed & D2 & D2 & D2 & D2 \\
\hline Map resolution (Å) & 3.0 & 4.0 & 3.7 & 3.0 \\
\hline FSC threshold & 0.143 & 0.143 & 0.143 & 0.143 \\
\hline Map resolution range $(\AA)$ & $2.9-3.9$ & $3.6-6.2$ & $3.6-6.4$ & $2.8-4.9$ \\
\hline \multicolumn{5}{|l|}{ Refinement } \\
\hline Initial model used (PDB code) & 4QLB & 4QLB & 3NBO, 4QLB & 3NBO, 4QLB \\
\hline Model Resolution (Å) & 3.1 & 4.1 & 3.7 & 3.1 \\
\hline FSC threshold & 0.5 & 0.5 & 0.5 & 0.5 \\
\hline Map sharpening $B$ factor $\left(\AA^{2}\right)$ & -68 & -143 & -95 & -51 \\
\hline \multicolumn{5}{|l|}{ Model composition } \\
\hline Nonhydrogen atoms & 21,172 & 21,196 & 20,240 & 20,372 \\
\hline Protein residues & 2618 & 2612 & 2488 & 2488 \\
\hline Ligands & 0 & $4 \mathrm{G} 6 \mathrm{P}$ & $4 \mathrm{G} 6 \mathrm{P}$ & 4 G6P, 4 GLC, 4 UDP \\
\hline \multicolumn{5}{|l|}{ B factors $\left(\AA^{2}\right)$} \\
\hline Protein & $5.90 / 77.05 / 29.87$ & $24.24 / 174.63 / 81.36$ & $22.90 / 242.10 / 116.12$ & $0.47 / 83.99 / 41.65$ \\
\hline Ligand & & $54.05 / 54.63 / 54.43$ & $30.68 / 34.74 / 32.41$ & $9.99 / 32.42 / 25.15$ \\
\hline \multicolumn{5}{|l|}{ R.m.s. deviations } \\
\hline Bond lengths ( $\AA$ ) & 0.004 & 0.003 & 0.002 & 0.003 \\
\hline Bond angles $\left({ }^{\circ}\right)$ & 0.542 & 0.592 & 0.535 & 0.589 \\
\hline \multicolumn{5}{|l|}{ Validation } \\
\hline MolProbity score & 1.48 & 1.58 & 1.67 & 1.93 \\
\hline Clashscore & 4.77 & 9.02 & 8.33 & 11.38 \\
\hline Poor rotamers (\%) & 0.13 & 0.00 & 0.00 & 0.37 \\
\hline \multicolumn{5}{|l|}{ Ramachandran plot } \\
\hline Favored (\%) & 96.43 & 97.52 & 96.64 & 94.78 \\
\hline Allowed (\%) & 3.57 & 2.48 & 3.56 & 5.22 \\
\hline Disallowed (\%) & 0.00 & 0.00 & 0.00 & 0.00 \\
\hline
\end{tabular}


bioRxiv preprint doi: https://doi.org/10.1101/2021.11.12.468446; this version posted November 13, 2021. The copyright holder for this preprint (which was not certified by peer review) is the author/funder, who has granted bioRxiv a license to display the preprint in perpetuity. It is made available under aCC-BY 4.0 International license.

Structural Basis of Human GYS1 Regulation

\section{References}

1. Roach, P.J. Glycogen and its metabolism. Curr Mol Med 2, 101-20 (2002).

2. Smythe, C. \& Cohen, P. The discovery of glycogenin and the priming mechanism for glycogen biogenesis. Eur J Biochem 200, 625-31 (1991).

3. Cid, E., Geremia, R.A., Guinovart, J.J. \& Ferrer, J.C. Glycogen synthase: towards a minimum catalytic unit? FEBS Lett 528, 5-11 (2002).

4. Thon, V.J., Khalil, M. \& Cannon, J.F. Isolation of human glycogen branching enzyme cDNAs by screening complementation in yeast. J Biol Chem 268, 7509-13 (1993).

5. Villar-Palasi, C. \& Larner, J. A uridine coenzyme-linked pathway of glycogen synthesis in muscle. Biochim Biophys Acta 30, 449 (1958).

6. Kaslow, H.R. \& Lesikar, D.D. Isozymes of glycogen synthase. FEBS Lett 172, 294-8 (1984).

7. Inoue, N., Matsukado, Y., Goto, S. \& Miyamoto, E. Localization of glycogen synthase in brain. J Neurochem 50, 400-5 (1988).

8. Leloir, L.F., Olavarria, J.M., Goldemberg, S.H. \& Carminatti, H. Biosynthesis of glycogen from uridine diphosphate glucose. Arch Biochem Biophys 81, 508-20 (1959).

9. Villar-Palasi, C. \& Guinovart, J.J. The role of glucose 6-phosphate in the control of glycogen synthase. FASEB J 11, 544-58 (1997).

10. Smith, C.H., Brown, N.E. \& Larner, J. Molecular characteristics of the totally dependent and independent forms of glycogen synthase of rabbit skeletal muscle. II. Some chemical characteristics of the enzyme protein and of its change on interconversion. Biochim Biophys Acta 242, 81-8 (1971).

11. Roach, P.J. Multisite and hierarchal protein phosphorylation. J Biol Chem 266, 14139-42 (1991).

12. Skurat, A.V., Wang, Y.\& Roach, P.J. Rabbit skeletal muscle glycogen synthase expressed in COS cells. Identification of regulatory phosphorylation sites. J Biol Chem 269, 25534-42 (1994).

13. Skurat, A.V. \& Roach, P.J. Phosphorylation of sites 3a and 3b (Ser640 and Ser644) in the control of rabbit muscle glycogen synthase. J Biol Chem 270, $12491-7$ (1995).

14. Jensen, J. \& Lai, Y.C. Regulation of muscle glycogen synthase phosphorylation and kinetic properties by insulin, exercise, adrenaline and role in insulin resistance. Arch Physiol Biochem 115, 13-21 (2009).

15. Baskaran, S. et al. Multiple glycogen-binding sites in eukaryotic glycogen synthase are required for high catalytic efficiency toward glycogen. J Biol Chem 286, 33999-4006 (2011).

16. Baskaran, S., Roach, P.J., DePaoli-Roach, A.A. \& Hurley, T.D. Structural basis for glucose-6phosphate activation of glycogen synthase. Proc Natl Acad Sci U S A 107, 17563-8 (2010).

17. Chikwana, V.M. et al. Structural basis for 2 '-phosphate incorporation into glycogen by glycogen synthase. Proceedings of the National Academy of Sciences of the United States of America 110, 20976-20981 (2013).

18. Mahalingan, K.K., Baskaran, S., DePaoli-Roach, A.A., Roach, P.J. \& Hurley, T.D. Redox Switch for the Inhibited State of Yeast Glycogen Synthase Mimics Regulation by Phosphorylation. Biochemistry 56, 179-188 (2017).

19. Kumar, G.S. et al. Identification of the substrate recruitment mechanism of the muscle glycogen protein phosphatase 1 holoenzyme. Science Advances 4(2018).

20. Christiansen, C. et al. The carbohydrate-binding module family 20-diversity, structure, and function. Febs Journal 276, 5006-5029 (2009).

21. Fong, N.M. et al. Identification of binding sites on protein targeting to glycogen for enzymes of glycogen metabolism. Journal of Biological Chemistry 275, 35034-35039 (2000).

22. Printen, J.A., Brady, M.J. \& Saltiel, A.R. PTG, a protein phosphatase 1-binding protein with a role in glycogen metabolism. Science 275, 1475-8 (1997).

23. Tang, B. et al. Discovery and Development of Small-Molecule Inhibitors of Glycogen Synthase. J Med Chem 63, 3538-3551 (2020).

24. Kakhlon, O. et al. Guaiacol as a drug candidate for treating adult polyglucosan body disease. JCI Insight 3(2018). 
bioRxiv preprint doi: https://doi.org/10.1101/2021.11.12.468446; this version posted November 13, 2021. The copyright holder for this preprint (which was not certified by peer review) is the author/funder, who has granted bioRxiv a license to display the preprint in perpetuity. It is made available under aCC-BY 4.0 International license.

Structural Basis of Human GYS1 Regulation

25. Buschiazzo, A. et al. Crystal structure of glycogen synthase: homologous enzymes catalyze glycogen synthesis and degradation. EMBO J 23, 3196-205 (2004).

26. Sheng, F., Jia, X., Yep, A., Preiss, J. \& Geiger, J.H. The crystal structures of the open and catalytically competent closed conformation of Escherichia coli glycogen synthase. J Biol Chem 284, 17796-807 (2009).

27. Horcajada, C., Guinovart, J.J., Fita, I. \& Ferrer, J.C. Crystal structure of an archaeal glycogen synthase: insights into oligomerization and substrate binding of eukaryotic glycogen synthases. J Biol Chem 281, 2923-31 (2006).

28. Zeqiraj, E. et al. Structural basis for the recruitment of glycogen synthase by glycogenin. Proc Natl Acad Sci U S A 111, E2831-40 (2014).

29. Hunter, R.W., Zeqiraj, E., Morrice, N., Sicheri, F. \& Sakamoto, K. Expression and purification of functional human glycogen synthase-1:glycogenin-1 complex in insect cells. Protein Expr Purif 108, 23-29 (2015).

30. Khanna, M. et al. Expression and purification of functional human glycogen synthase-1 (hGYS1) in insect cells. Protein Expr Purif 90, 78-83 (2013).

31. Sheng, F., Yep, A., Feng, L., Preiss, J. \& Geiger, J.H. Oligosaccharide binding in Escherichia coli glycogen synthase. Biochemistry 48, 10089-97 (2009).

32. Roach, P.J., Takeda, Y. \& Larner, J. Rabbit skeletal muscle glycogen synthase. I. Relationship between phosphorylation state and kinetic properties. J Biol Chem 251, 1913-9 (1976).

33. Pederson, B.A., Cheng, C., Wilson, W.A. \& Roach, P.J. Regulation of glycogen synthase. Identification of residues involved in regulation by the allosteric ligand glucose-6-P and by phosphorylation. J Biol Chem 275, 27753-61 (2000).

34. Roach, R.J. \& Larner, J. Covalent phosphorylation in the regulation glycogen synthase activity. Mol Cell Biochem 15, 179-200 (1977).

35. Palm, D.C., Rohwer, J.M. \& Hofmeyr, J.H. Regulation of glycogen synthase from mammalian skeletal muscle--a unifying view of allosteric and covalent regulation. FEBS J 280, 2-27 (2013).

36. Hanashiro, I. \& Roach, P.J. Mutations of muscle glycogen synthase that disable activation by glucose 6-phosphate. Arch Biochem Biophys 397, 286-92 (2002).

37. Bouskila, M. et al. Allosteric regulation of glycogen synthase controls glycogen synthesis in muscle. Cell Metab 12, 456-66 (2010).

38. Wang, Y. \& Roach, P.J. Inactivation of rabbit muscle glycogen synthase by glycogen synthase kinase-3. Dominant role of the phosphorylation of Ser-640 (site-3a). J Biol Chem 268, 2387680 (1993).

39. Skurat, A.V., Dietrich, A.D. \& Roach, P.J. Glycogen synthase sensitivity to insulin and glucose-6-phosphate is mediated by both $\mathrm{NH} 2-$ and $\mathrm{COOH}$-terminal phosphorylation sites. Diabetes 49, 1096-100 (2000).

40. Bollen, M., Peti, W., Ragusa, M.J. \& Beullens, M. The extended PP1 toolkit: designed to create specificity. Trends Biochem Sci 35, 450-8 (2010).

41. Armstrong, C.G., Browne, G.J., Cohen, P. \& Cohen, P.T. PPP1R6, a novel member of the family of glycogen-targetting subunits of protein phosphatase 1. FEBS Lett 418, 210-4 (1997).

42. Liu, J. \& Brautigan, D.L. Glycogen synthase association with the striated muscle glycogentargeting subunit of protein phosphatase-1. Synthase activation involves scaffolding regulated by beta-adrenergic signaling. J Biol Chem 275, 26074-81 (2000).

43. Douillard-Guilloux, G. et al. Restoration of muscle functionality by genetic suppression of glycogen synthesis in a murine model of Pompe disease. Hum Mol Genet 19, 684-96 (2010).

44. Clayton, N.P. et al. Antisense Oligonucleotide-mediated Suppression of Muscle Glycogen Synthase 1 Synthesis as an Approach for Substrate Reduction Therapy of Pompe Disease. Molecular Therapy-Nucleic Acids 3(2014).

45. Kollberg, G. et al. Brief report: Cardiomyopathy and exercise intolerance in muscle glycogen storage disease 0. New England Journal of Medicine 357, 1507-1514 (2007).

46. Cameron, J.M. et al. Identification of a novel mutation in GYS1 (muscle-specific glycogen synthase) resulting in sudden cardiac death, that is diagnosable from skin fibroblasts. Mol Genet Metab 98, 378-82 (2009). 
bioRxiv preprint doi: https://doi.org/10.1101/2021.11.12.468446; this version posted November 13, 2021. The copyright holder for this preprint (which was not certified by peer review) is the author/funder, who has granted bioRxiv a license to display the preprint in perpetuity. It is made available under aCC-BY 4.0 International license.

Structural Basis of Human GYS1 Regulation

\section{Methods}

Cloning, expression, and purification of GYS1:GYG1 complexes. DNA encoding the full-length genes of human GYS1 (IMAGE: 3143019) and GYG1 (IMAGE: 3504538; isoform GN-1L with UniProt ID P46976-1) were amplified from a cDNA clone and subcloned into the FastBac ${ }^{\text {TM}}$-Dual vector (Life Technologies) with an N-terminal His $_{6}$-tag and a TEV protease cleavage site on GYS1. The GYG1 ${ }^{\text {p.Y195F }}$ mutant was generated from this plasmid using the QuickChange mutagenesis kit (Stratagene). Codon optimised genes for GYS1 and aa 264/294-350 GYG1 (GYG1 ${ }^{\Delta C D}$ ) (with a stop codon) interspersed with a SV40 terminator and a polyhedrin promotor were artificially synthesised (Twist Biosciences). Codon optimised sequences for either a N-terminal TEV cleavable MBP-His 6 , His $_{6}$-GST, or His 6 -GFP tag was appended to the GYG1 gene to allow purification. The resulting bistronic fragment was then inserted into pFB-CT10HF-LIC for insect cell expression. All GYS1:GYG1 complexes were expressed in Sf9 cells grown in Sf-900 ${ }^{\mathrm{TM}}$ III SFM (Life Technologies). Cell pellets were harvested, homogenized in lysis buffer $(50 \mathrm{mM}$ sodium phosphate $\mathrm{pH} 7.5,500 \mathrm{mM}$ $\mathrm{NaCl}, 5 \%$ glycerol, $0.5 \mathrm{mM}$ TCEP, $10 \mathrm{mM}$ imidazole) and insoluble material was removed by centrifugation. The GYS1:GYG1 complexes were purified by affinity (Ni-Sepharose; GE Healthcare) and size-exclusion (Superose 6; GE Healthcare) chromatography. Protein was treated with His-tagged TEV protease overnight at $4{ }^{\circ} \mathrm{C}$, and then passed over Ni-Sepharose resin to remove the TEV protease and uncleaved protein. Purified complexes were concentrated to $10-20 \mathrm{mg} / \mathrm{mL}$ and stored in storage buffer ( $25 \mathrm{mM}$ HEPES pH 7.5, $500 \mathrm{mM} \mathrm{NaCl}, 5 \%$ glycerol, $0.5 \mathrm{mM}$ TCEP) at $-80{ }^{\circ} \mathrm{C}$.

Cryo-EM sample preparation and data acquisition. GYS1:GYG1 ${ }^{\triangle \mathrm{CD}}$ was diluted to $0.75 \mathrm{mg} / \mathrm{ml}$ into $25 \mathrm{mM}$ HEPES, pH 7.5, $200 \mathrm{mM} \mathrm{NaCl}, 2.0 \mathrm{mM}$ TCEP, $0.05 \%(\mathrm{v} / \mathrm{v})$ tween-20 for the as purified, inhibited state. For the activated states of GYS1:GYG1 ${ }^{\triangle \mathrm{CD}}$ was diluted to 0.75 or $0.5 \mathrm{mg} / \mathrm{ml}$ into 25 $\mathrm{mM}$ HEPES, pH 7.5, $200 \mathrm{mM} \mathrm{NaCl}, 2.0 \mathrm{mM}$ TCEP, 0.05\% (v/v) tween-20, $5 \mathrm{mM}$ Glc6P, and $5 \mathrm{mM}$ UDP-Glc when stated. Grids were prepared using a FEI Vitrobot Mark III at $4{ }^{\circ} \mathrm{C}$ and $100 \%$ humidity. $3 \mu 1$ of sample was applied to a plasma treated gold coated R 1.2/1.3 300 mesh holey carbon grid (Quantifoil), with a blot force of 0 , a blot time of 3 seconds and a wait time of 10 seconds.

Movies of GYS1:GYG1 ${ }^{\Delta \mathrm{CD}}$ as purified and in the presence of Glc6P were collected during the same session at the Midlands Regional CryoEM Facility on a FEI Titan Krios equipped with a K3 (Gatan) direct electron detector operating in super-resolution mode. Images were imaged at $300 \mathrm{kV}$ with a magnification of $81,000 \times$, corresponding to a physical pixel size of $1.086 \AA$ (super resolution pixel size of $0.543 \AA$ ). 45 frames over 5 seconds were recorded with a defocus range of $-0.8 \mu \mathrm{m}$ to $2.3 \mu \mathrm{m}$ with a total dose of $\left(1.22 \mathrm{e}^{-} \mathrm{A}^{-2}\right.$ per frame). Movies of GYS1+GYG1 ${ }^{\Delta \mathrm{CD}}$ in the presence of Glc6P and UDP-Glc were collected at eBIC (Diamond Light Source) on a FEI Titan Krios equipped with a K3 (Gatan) direct electron detector operating in super-resolution mode. Images were imaged at $300 \mathrm{kV}$ with a magnification of $81,000 \times$, corresponding to a physical pixel size of $1.06 \AA$ (super resolution pixel size of $0.53 \AA$ ). 50 frames over 3.4 seconds were recorded with a defocus range of $0.8 \mu \mathrm{m}$ to $-2.3 \mu \mathrm{m}$ with a total dose of $\left(1.00 \mathrm{e}^{-} \mathrm{A}^{-2}\right.$ per frame $)$.

All datasets were corrected for beam induced motion with MotionCor $2^{47}$ and CTF was estimated using CTFFIND-4.1 ${ }^{48}$. Particles were auto-picked using the Relion 3.1.1 ${ }^{49}$. Laplacian of Gaussian function and all further processing was done in Relion 3.1.1. For more detailed information on the processing workflow for all datasets please see extended data figures 3, 7, 8, and 10. All final maps were automatically sharpened in Relion 3.1.1. and for all but the inhibited state, locally filtered by resolution using LocRes. LAFTER ${ }^{50}$ maps were produced in aid of model building. Relion extracted particles and maps were imported into CryoSPARC v3.1.0 to use for 3D variability analysis ${ }^{51}$ with five components. Components were visualized by 3DVA simple display with 20 frames each using UCSF Chimera.

Model fitting, refinement, and validation. Initial models of human GYS1 and GYG1 were built using the SWISS-MODEL server ${ }^{52}$ with structures of the C. elegans GYS1:GYG1 ${ }^{\Delta \mathrm{CD}}$ and the activated Glc6P bound state of yeast Gsy2p (PDB 4QLB and 3NB0 respectively) as a template. GYS1 models were docked into maps using Molrep ${ }^{53}$ and GYG1 was manually docked using UCSF Chimera. For the

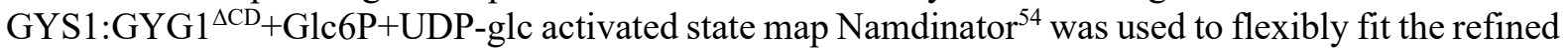


bioRxiv preprint doi: https://doi.org/10.1101/2021.11.12.468446; this version posted November 13, 2021. The copyright holder for this preprint (which was not certified by peer review) is the author/funder, who has granted bioRxiv a license to display the preprint in perpetuity. It is made available under aCC-BY 4.0 International license.

Structural Basis of Human GYS1 Regulation

GYS1:GYG1 ${ }^{\triangle \mathrm{CD}}+$ Glc6P activated model. Further model building and manual refinement was performed in COOT $^{55}$ followed by iterative cycles of real-space refinement performed in Phenix ${ }^{56}$. Final models were validated using MolProbity ${ }^{57}$. Figures were created in UCSF Chimera and Chimera $\mathrm{X}^{58}$.

Dephosphorylation of GYS1:GYG1 complexes. GYS1:GYG1 complexes at $5.0 \mathrm{mg} / \mathrm{ml}$ were dephosphorylated with $0.5 \mathrm{mg} / \mathrm{ml}$ PP1c in $25 \mathrm{mM}$ HEPES, pH 7.5, $200 \mathrm{mM} \mathrm{NaCl}, 2.0 \mathrm{mM}$ TCEP, 2.0 $\mathrm{mM} \mathrm{MnCl} l_{2}$ at room temperature for one hour. Reactions were halted by putting them into ice.

UDP-Glo activity assay. The activity of GYS1:GYG1 complexes was measured using the UDP-Glo ${ }^{\mathrm{TM}}$ glycosyltransferase assay (Promega) according to manufacturer's instructions. To measure activity 10 $\mu \mathrm{L} /$ well of reaction containing $100 \mathrm{nM}$ GYS1:GYG1, $1 \mathrm{mM}$ UDP-glucose, $0.5 \mathrm{mg} / \mathrm{ml}$ glycogen, and $10 \mathrm{mM}$ glucose-6-phosphate in assay buffer (25 mM HEPES, pH 7.5, $200 \mathrm{mM} \mathrm{NaCl}, 0.5 \mathrm{mM}$ TCEP) were dispensed into 384-well assay plates (Greiner). Following a 60 minutes incubation at room temperature, $10 \mu \mathrm{L}$ of UDP-Glo Plus detection reagent was added (final assay volume: $20 \mu \mathrm{L} / w e l l$ ), and after a further 60 minutes room temperature incubation, luminescence was detected using a SpectraMax M3 (Molecular Devices).

Cloning, expression, and purification of GYG1 and PTG. GYG1 was purified as previously described $^{59}$. Human PTG (PPP1R3C) aa 134-259 (IMAGE clone: 4245774) was subcloned into the pNIC28-Bsa4 vector (GenBank accession no. EF198106) incorporating an N-terminal TEV-cleavable His $_{6}$-tag. PTG was cultured in $6 \mathrm{~L}$ of auto-induction Terrific Broth (Formedium) at $37^{\circ} \mathrm{C}$ and induced overnight at $18{ }^{\circ} \mathrm{C}$. Cell pellets were harvested, homogenized in lysis buffer $(50 \mathrm{mM}$ sodium phosphate $\mathrm{pH} 7.5,500 \mathrm{mM} \mathrm{NaCl}, 5 \%$ glycerol, $0.5 \mathrm{mM}$ TCEP, $10 \mathrm{mM}$ imidazole) and insoluble material was removed by centrifugation. The supernatant was purified by affinity (Ni-Sepharose; GE Healthcare) and size-exclusion (Superdex 75; GE Healthcare) chromatography. Purified protein was concentrated to $10-20 \mathrm{mg} / \mathrm{mL}$ and stored in storage buffer $(25 \mathrm{mM}$ HEPES $\mathrm{pH} 7.5,500 \mathrm{mM} \mathrm{NaCl}, 5 \%$ glycerol, 0.5 $\mathrm{mM}$ TCEP) at $-80^{\circ} \mathrm{C}$.

Talon pull down assay. His-PPP1R3C $(1.0 \mathrm{mg} / \mathrm{ml})$ was pre-incubated with either GYS1:GYG1 complex $(0.25 \mathrm{mg} / \mathrm{ml})$ or GYG1 $(0.5 \mathrm{mg} / \mathrm{ml})$ for $30 \mathrm{~min}$ at $4{ }^{\circ} \mathrm{C}$ in a total volume of $100 \mu 1$. Next $80 \mu 1$ of a 50\% slurry of Talon resin (Clontech) in binding buffer ( $25 \mathrm{mM}$ HEPES, pH 7.5, $100 \mathrm{mM} \mathrm{NaCl}$, $1 \mathrm{mM}$ TCEP, $0.2 \%$ Tween 20) was added and incubated for a further $30 \mathrm{~min}$ at $4{ }^{\circ} \mathrm{C}$. The resin was washed with $2 \mathrm{ml}$ binding buffer with $10 \mathrm{mM}$ imidazole and eluted with $40 \mu 14 \times$ SDS PAGE sample buffer. Samples were run on SDS-PAGE and stained with Coomassie blue.

Thermal shift assay. His-PPP1R3C or GYS1:GYG1 complex was diluted in thermal shift buffer (25 mM HEPES, pH 7.5, $200 \mathrm{mM} \mathrm{NaCl}, 2.0 \mathrm{mM}$ TCEP) to $0.1 \mathrm{mg} / \mathrm{ml}$ with SYPRO-Orange (Invitrogen) diluted $1000 \mathrm{X}$ and with ligand at $1 \mathrm{mM}$ in a total volume of $20 \mu 1$. Protein with ligand was incubated for $5 \mathrm{~min}$ at room temperature in 96-well PCR plates, before the addition of SYPRO-Orange. A Mx3005p RT-PCR machine (Stratagene) with excitation and emission filters of 492 and $610 \mathrm{~nm}$, respectively was used to measure temperature shifts.

Blue-Native PAGE. Blue-NATIVE PAGE was carried out as previously described and according to manufacturer's instructions (Life Technologies). His-PPP1R3C, GYS1:GYG1 complex, and/or GYG1 were diluted in thermal shift buffer (25 mM HEPES, pH 7.5, $200 \mathrm{mM} \mathrm{NaCl}, 1.0 \mathrm{mM}$ TCEP) was preincubated for $5 \mathrm{~min}$ at room temperature. All blue-native PAGE experiments were performed thrice independently.

\section{Data availability}

Structures and EM maps of GYS1:GYG1 ${ }^{\triangle C D}$ inhibited state (EMDB-13743, PDB-7Q0B), GYS1:GYG1 ${ }^{\Delta \mathrm{CD}}+\mathrm{Glc} 6 \mathrm{P}$ inhibited like-state (EMDB-13751, PDB-7Q0S), GYS1:GYG1 ${ }^{\Delta \mathrm{CD}+\mathrm{Glc} 6 \mathrm{P}}$ activated state (EMDB-13752, PDB-7Q12), and GYS1:GYG1 ${ }^{\triangle \mathrm{CD}}+\mathrm{Glc} 6 \mathrm{P}+\mathrm{UDP}-\mathrm{Glc}$ activated state (EMDB-13753, PDB-7Q13) have been deposited to the EMDB and PDB databases. 
bioRxiv preprint doi: https://doi.org/10.1101/2021.11.12.468446; this version posted November 13, 2021. The copyright holder for this preprint (which was not certified by peer review) is the author/funder, who has granted bioRxiv a license to display the preprint in perpetuity. It is made available under aCC-BY 4.0 International license.

Structural Basis of Human GYS1 Regulation

\section{References}

47. Zheng, S.Q. et al. MotionCor2: anisotropic correction of beam-induced motion for improved cryo-electron microscopy. Nat Methods 14, 331-332 (2017).

48. Rohou, A. \& Grigorieff, N. CTFFIND4: Fast and accurate defocus estimation from electron micrographs. Journal of Structural Biology 192, 216-221 (2015).

49. Zivanov, J. et al. New tools for automated high-resolution cryo-EM structure determination in RELION-3. eLife 7, 1-22 (2018).

50. Ramlaul, K., Palmer, C.M. \& Aylett, C.H.S. A Local Agreement Filtering Algorithm for Transmission EM Reconstructions. J Struct Biol 205, 30-40 (2019).

51. Punjani, A. \& Fleet, D.J. 3D variability analysis: Resolving continuous flexibility and discrete heterogeneity from single particle cryo-EM. J Struct Biol 213, 107702 (2021).

52. Waterhouse, A. et al. SWISS-MODEL: homology modelling of protein structures and complexes. Nucleic Acids Res 46, W296-W303 (2018).

53. Vagin, A. \& Teplyakov, A. Molecular replacement with MOLREP. Acta Crystallogr D Biol Crystallogr 66, 22-5 (2010).

54. Kidmose, R.T. et al. Namdinator - automatic molecular dynamics flexible fitting of structural models into cryo-EM and crystallography experimental maps. IUCrJ 6, 526-531 (2019).

55. Emsley, P. \& Cowtan, K. Coot: model-building tools for molecular graphics. Acta Crystallogr D Biol Crystallogr 60, 2126-32 (2004).

56. Afonine, P.V. et al. Real-space refinement in PHENIX for cryo-EM and crystallography. Acta Crystallogr D Struct Biol 74, 531-544 (2018).

57. Chen, V.B. et al. MolProbity: all-atom structure validation for macromolecular crystallography. Acta Crystallogr D Biol Crystallogr 66, 12-21 (2010).

58. Pettersen, E.F. et al. UCSF ChimeraX: Structure visualization for researchers, educators, and developers. Protein Sci 30, 70-82 (2021).

59. Chaikuad, A. et al. Conformational plasticity of glycogenin and its maltosaccharide substrate during glycogen biogenesis. Proceedings of the National Academy of Sciences of the United States of America 108, 21028-21033 (2011).

\section{Acknowledgements}

We thank all members of the SGC Biotech team especially Dong Wang for her molecular biology support. We thank Sean Froese for GYG1 constructs cloned at the SGC. We thank the Oxford Particle Imaging Centre (OPIC) electron microscopy facility for initial grid screening and data collection. We also want to thank Laura Díaz Sáez for her help in the initial EM screening and data collection. We acknowledge The Midlands Regional CryoEM Facility at the Leicester Institute of Structural and Chemical Biology (LISCB), major funding from MRC (MC_PC_17136). We specifically want to thank Christos Savva for assistance and guidance in collection of data. We acknowledge the Diamond Light Source for access and support to the UK's Electron Bio-imaging Centre (eBIC, under BAG proposal EM20223) funded by the Wellcome Trust, MRC, and BBRSC. We specifically want to thank Peter Harrison for assistance in collection of data at eBIC. We also wish to thank Brian Marsden and Chris Sluman for their bioinformatics support. The Structural Genomics Consortium is a registered charity (Number 1097737) that receives funds from AbbVie, Bayer Pharma AG, Boehringer Ingelheim, Canada Foundation for Innovation, Eshelman Institute for Innovation, Genome Canada, Innovative Medicines Initiative (EU/EFPIA) [ULTRA-DD grant no. 115766], Janssen, Merck \& Co., Novartis Pharma AG, Ontario Ministry of Economic Development and Innovation, Pfizer, São Paulo Research FoundationFAPESP, Takeda, and Wellcome Trust [092809/ Z/10/Z]. I.M.F. was supported by CNPq, Brazilian National Council for Scientific and Technological Development. T.J.M. and W.W.Y. also gratefully received Emerging Science Funds from Pfizer Worldwide Research and Development.

\section{Author contributions}

T.J.M., A.B., and W.W.Y. designed the experiments. T.J.M. designed the GYS1:GYG1 ${ }^{\Delta C D}$ constructs, expressed and purified all GYS1:GYG1 complexes, screened and collected EM data, analyzed and refined all GYS1:GYG1 ${ }^{\Delta \mathrm{CD}}$ structures. I.M.F. and L.S. carried out initial construct cloning, testing and 
bioRxiv preprint doi: https://doi.org/10.1101/2021.11.12.468446; this version posted November 13, 2021. The copyright holder for this preprint (which was not certified by peer review) is the author/funder, who has granted bioRxiv a license to display the preprint in perpetuity. It is made available under aCC-BY 4.0 International license.

Structural Basis of Human GYS1 Regulation

optimization. D.S.F. expressed and purified the GYG1 constructs. T.J.M. expressed and purified the PTG construct and carried out all biochemical experiments. T.J.M. and W.W.Y. carried out the data analysis and wrote the manuscript with contributions from all authors 
bioRxiv preprint doi: https://doi.org/10.1101/2021.11.12 468446; this version posted November 13, 2021. The copyright holder for this preprint (which was not certified by peer review) is the author/funder, who has granted bioRxiv a license to display the preprint in perpetuity. It is made available under aCC-BY 4.0 International license.

a

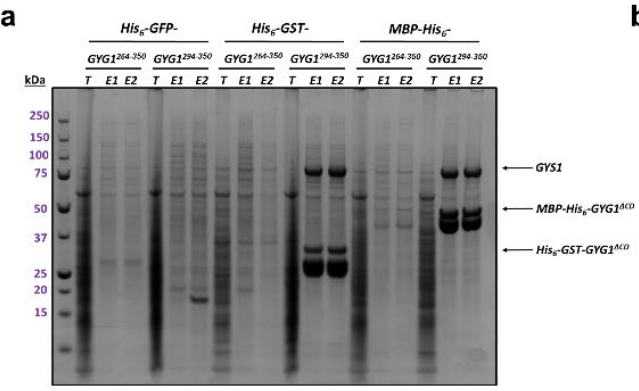

d
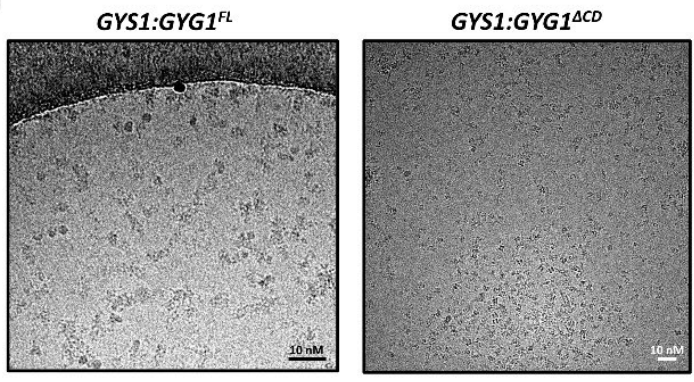

b

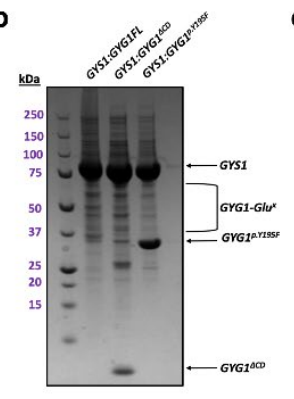

c

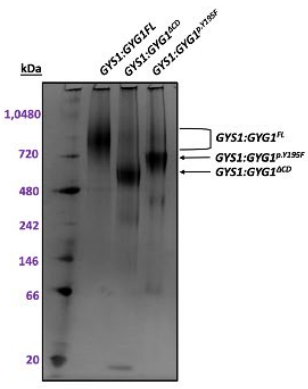

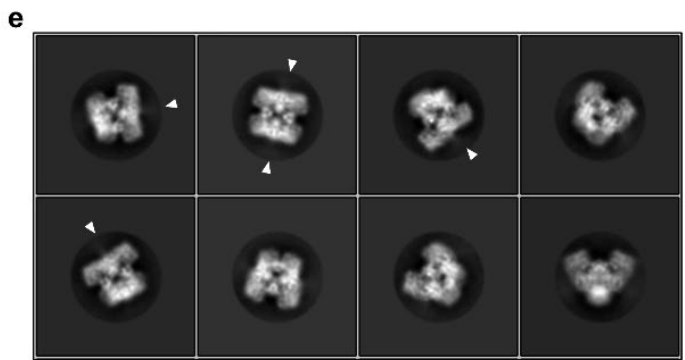

Extended Data Fig. 1 | Purification and preliminary characterization of GYS1:GYG1 complexes. a, Coomassie stained SDS-PAGE of small-scale test purifications of GYS1 complexed with differently tagged truncated GYG1. b, Coomassie stained SDS-PAGE of the three GYS1:GYG1 complexes used in this study. c, Blue native PAGE of the three GYS1:GYG1 complexes used in this study. d, Example micrographs of GYS1:GYG1 ${ }^{\mathrm{FL}}$ and GYS1:GYG1 ${ }^{\triangle \mathrm{CD}}$ complexes collected using a Glacios microscope. e, 2D classes of the GYS1:GYG1 ${ }^{\Delta \mathrm{CD}}$ complex from an initial dataset collected using a Glacios microscope. Arrows indicate regions of fuzzy density protruding from an inter-subunit interface. 

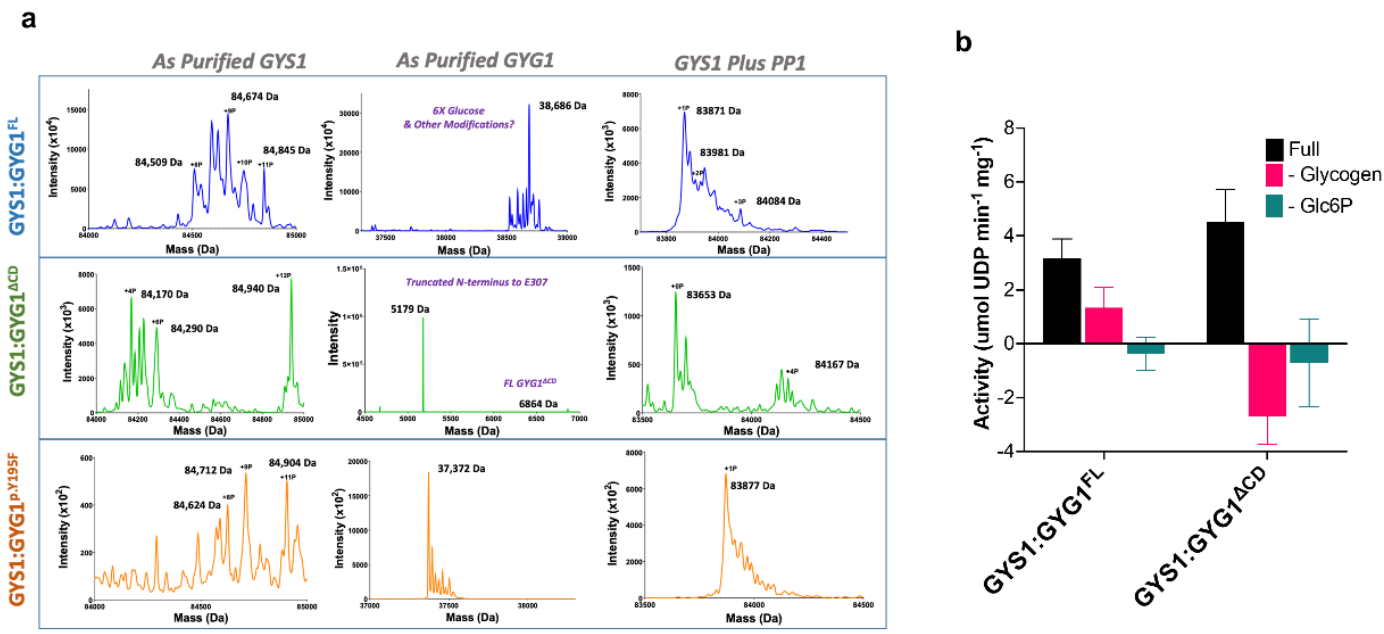

Extended Data Fig. 2 | Mass-spectrometry and activity of the three GYS1:GYG1 constructs. a, Denaturing mass-spectra of GYS1 and GYG1, as purified and treated with PP1. b, UDP-Glo activity assay of the three GYS1:GYG1 constructs without and with exogenous glycogen. 'Full' is the activity assay with all substrates. '- Glycogen' is the assay carried out in the absence of exogenously added glycogen. '- Glc6P' is the assay carried out in the absence of Glc6P. Median and standard deviation of activity is shown ( $n=3$ technical repeats). 
bioRxiv preprint doi: https://doi.org/10.1101/2021.11.12 468446; this version posted November 13, 2021. The copyright holder for this preprint (which was not certified by peer review) is the author/funder, who has granted bioRxiv a license to display the preprint in perpetuity. It is made available under aCC-BY 4.0 International license.

a

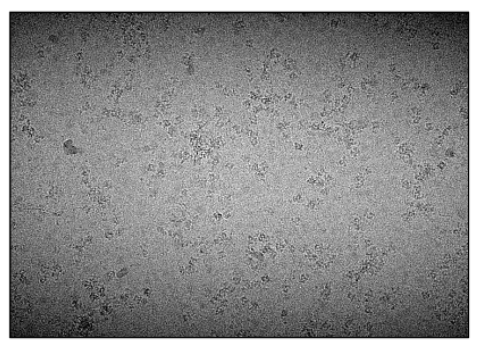

b

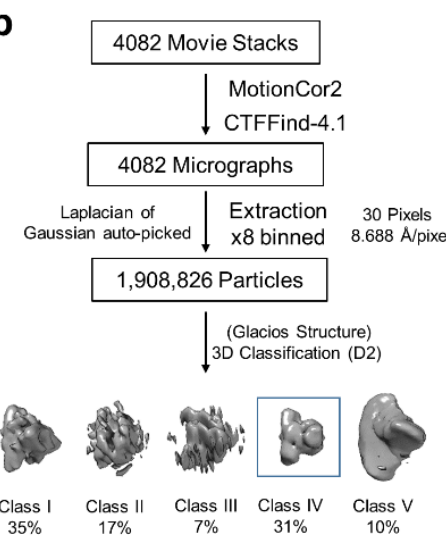

${ }_{35 \%} \quad{ }_{17 \%} \quad 7_{7 \%} \quad{ }_{31 \%} \quad{ }_{10 \%}$
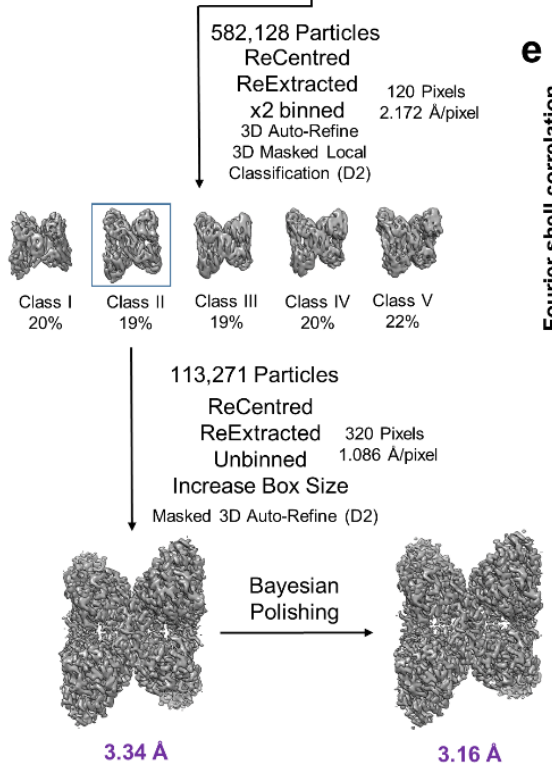

C

d

e
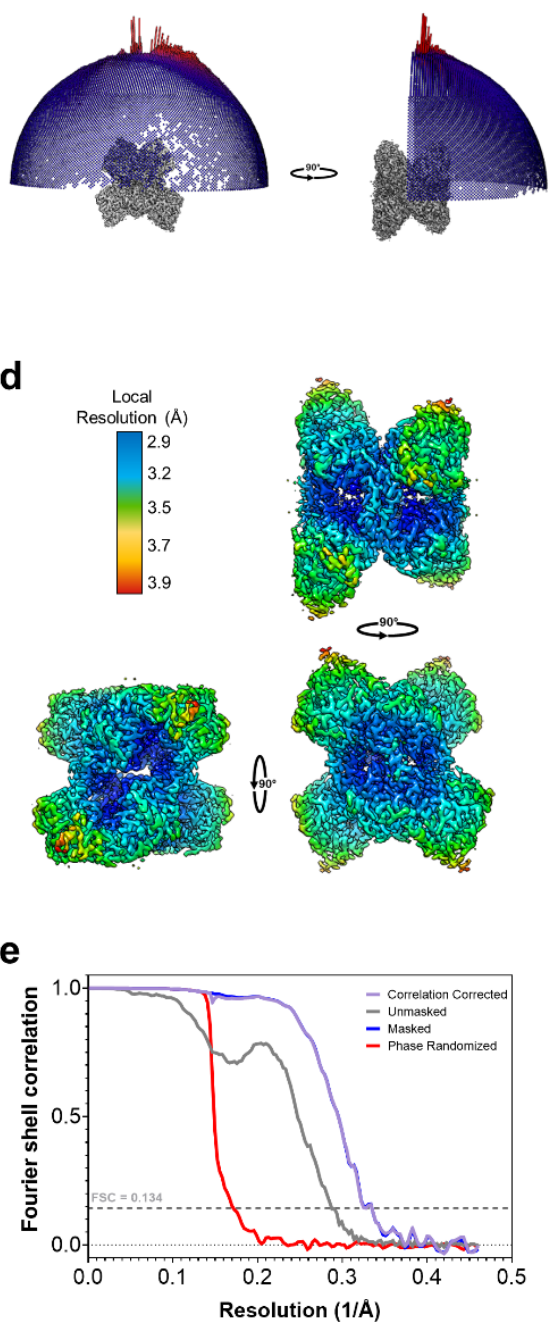

$2 x$ Beam tilt \& per particle particle

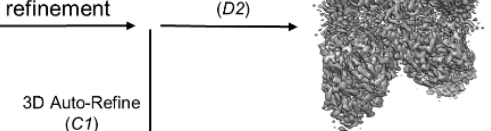

$2.99 \mathrm{~A}$

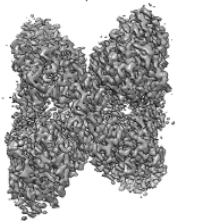

3.30 A

Extended Data Fig. 3 | Image processing workflow of the GYS1:GYG1 ${ }^{\Delta C D}$ inhibited state. a, Representative K3 micrograph of the GYS1:GYG1 ${ }^{\Delta \mathrm{CD}}$ inhibited state. b, Processing flow chart of the GYS1+GYG1 ${ }^{\triangle \mathrm{CD}}$ inhibited state. c, Angular distribution of the $3.0 \AA \mathrm{GYS1}: \mathrm{GYG}{ }^{1 \mathrm{CD}}$ inhibited state map. d, Local resolution variation of the $3.0 \AA \mathrm{GYS} 1: \mathrm{GYG}^{\triangle \mathrm{CD}}$ inhibited state map. e, FSC curve of the $3.0 \AA$ GYS1:GYG1 ${ }^{\Delta C D}$ inhibited state map. 


\section{a}
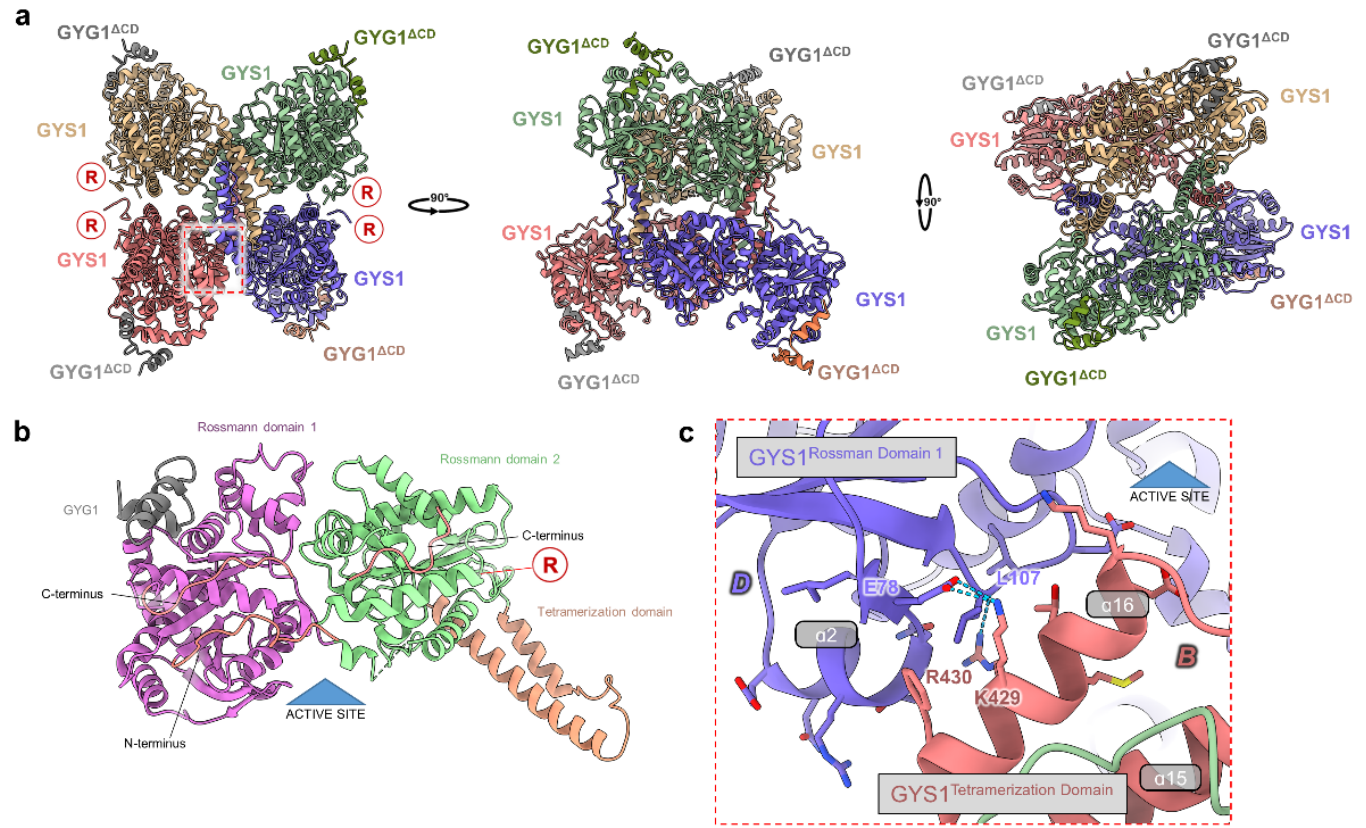

Extended Data Fig. 4 | Structure of the GYS1:GYG1 ${ }^{\Delta C D}$ inhibited state. a, Model of the GYS1:GYG1 ${ }^{\triangle \mathrm{CD}}$ inhibited state in three orthogonal views. R represents the location of the regulatory helix. b. Structural model of a GYS1:GYG1 ${ }^{\triangle \mathrm{CD}}$ subunit showing the three domains of GYS1 as well as the GYG1 C-terminus. c, Close up of the inter-subunit interactions close to the active site cleft. 
bioRxiv preprint doi: https://doi.org/10.1101/2021.11.12 468446; this version posted November 13,2021 . The copyright holder for this preprint (which was not certified by peer review) is the author/funder, who has granted bioRxiv a license to display the preprint in perpetuity. It is made available under aCC-BY 4.0 International license.

Structural Basis of Human GYS1 Regulation

b
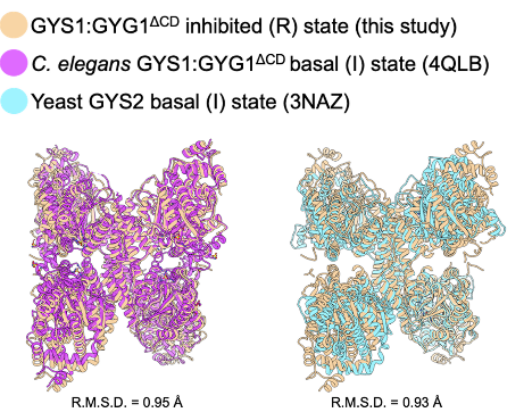

R.M.S.D. $=0.93 \mathrm{~A}$
GYS1:GYG1 $1 \mathrm{CD}$ inhibited (R) state (this study)

C. elegans GYS1:GYG $1 \triangle{ }^{\triangle C D}$ basal (I) state (4QLB)

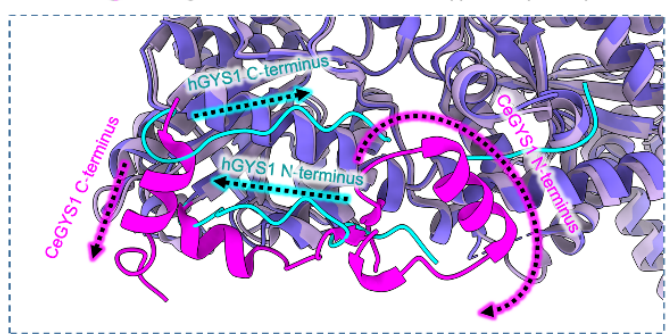

GYS1:GYG1 $\triangle \mathrm{CD}$ inhibited (R) state (this study)

C. elegans $\mathrm{GYS} 1 \mathrm{GYG}{ }^{\triangle C D}$ basal (I) state (4QLB)
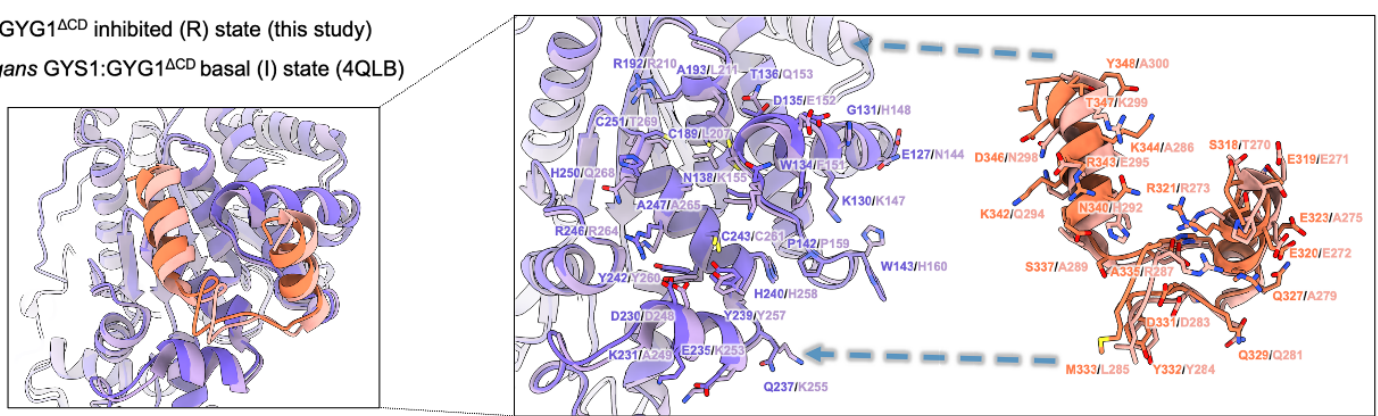

Extended Data Fig. 5 | Structural comparison of the GYS1:GYG1 ${ }^{\triangle C D}$ inhibited state with the $C$. elegans gys-1 and yeast Gsy2p basal/intermediate state structures. a, Structural alignment of the inhibited/T state of the human GYS1:GYG1 ${ }^{\Delta \mathrm{CD}}$ complex with the basal/I states of yeast gsy2p and $C$. elegans GYS1:GYG1 ${ }^{\triangle \mathrm{CD}}$ complex. $\mathbf{b}, \mathrm{A}$ zoom in view of the GYG1 interacting region of GYS1 of human and C. elegans. c, A structural alignment of the inhibited/T state of human GYS1 against the basal/I state of $C$. elegans GYS1 highlighting the different trajectories of the $\mathrm{N}$ - and C-termini. 
bioRxiv preprint doi: https://doi.org/10.1101/2021.11.12 468446; this version posted November 13,2021 . The copyright holder for this preprint (which was not certified by peer review) is the author/funder, who has granted bioRxiv a license to display the preprint in perpetuity. It is made available under aCC-BY 4.0 International license.

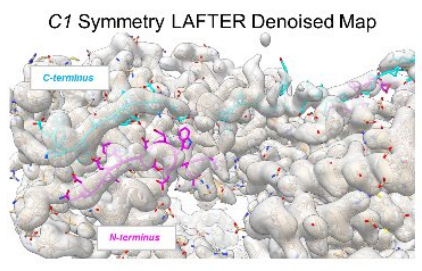

D2 Symmetry LAFTER Denoised Map

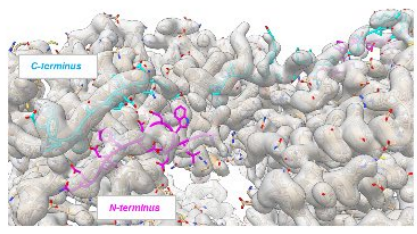

b

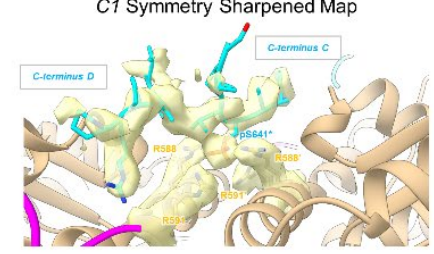

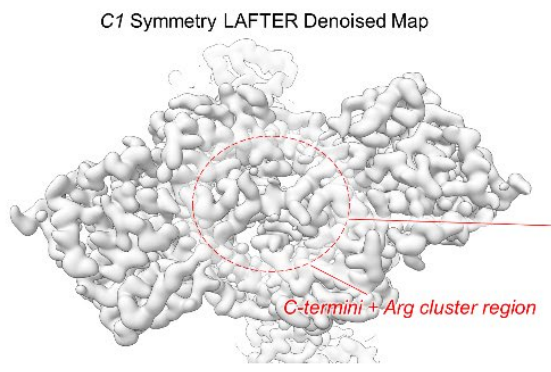

D2 Symmetry LAFTER Denoised Map

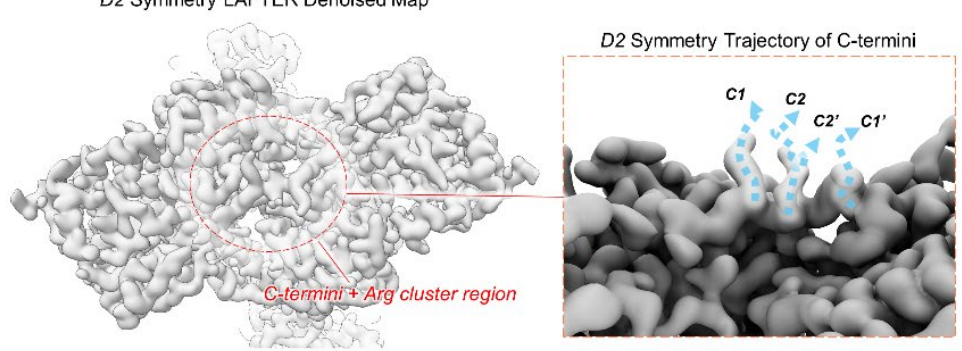

Structural Basis of Human GYS1 Regulation

Extended Data Fig. 6 | Modelling of the N- and C- termini of the inhibited/T state of the GYS1:GYG1 complex. a, Fitting of the $\mathrm{N}$ - and C- termini model into the $C 1$ and $D 2$ symmetry LAFTER denoised maps. b, Fitting of the phosphorylated C- termini model into the sharpened $C 1$ symmetry map. c, Views of the regulatory dimeric interface of the $\mathrm{C} 1$ and D2 symmetry LAFTER maps. The phosphorylated C-termini region density is symmetric in both maps. D, Predicted directions of the phosphorylated C-termini in C1 and D2 symmetry LAFTER denoised maps. The C-termini are predicted to continue away from the dimeric regulatory interface from two adjacent but different locations. 
bioRxiv preprint doi: https://doi.org/10.1101/2021.11.12 468446; this version posted November 13, 2021. The copyright holder for this preprint (which was not certified by peer review) is the author/funder, who has granted bioRxiv a license to display the preprint in perpetuity. It is made available under aCC-BY 4.0 International license.

Structural Basis of Human GYS1 Regulation

a

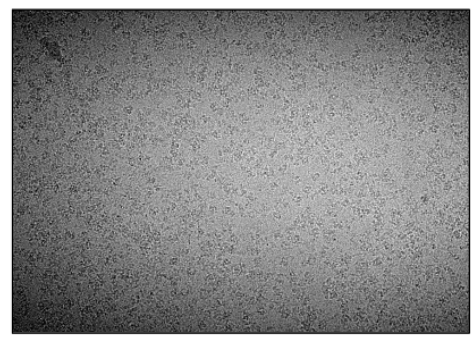

b

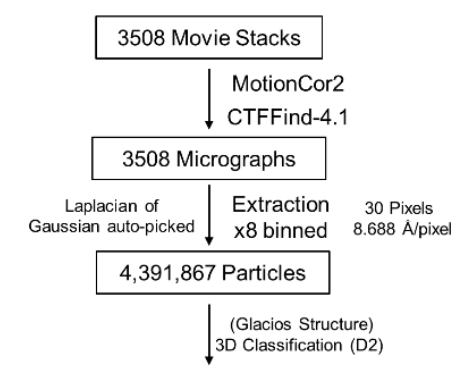

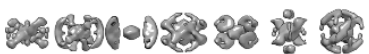

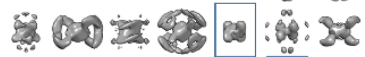
3ำ $259600000 \%$

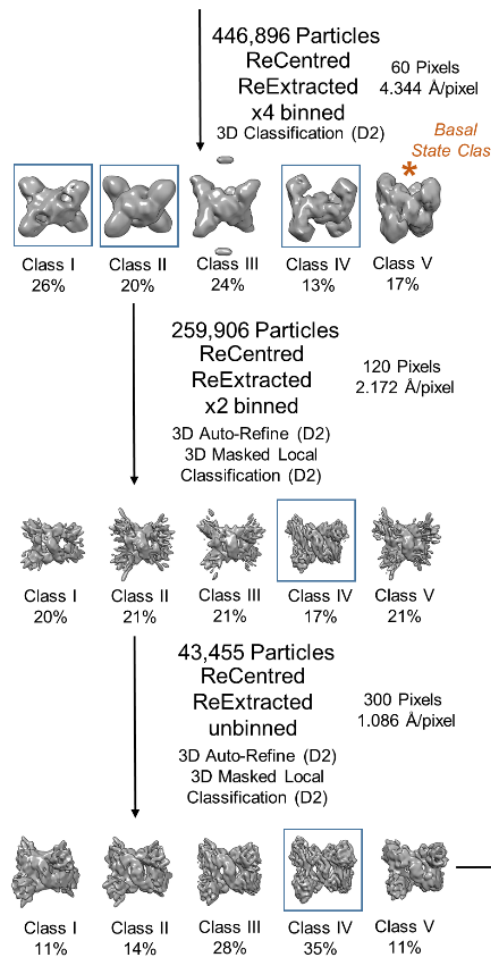

C

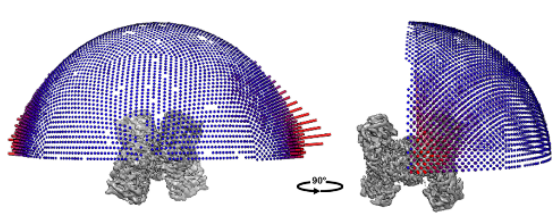

d
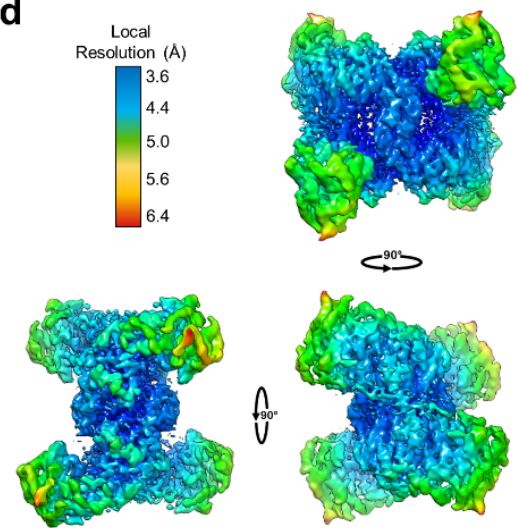

e
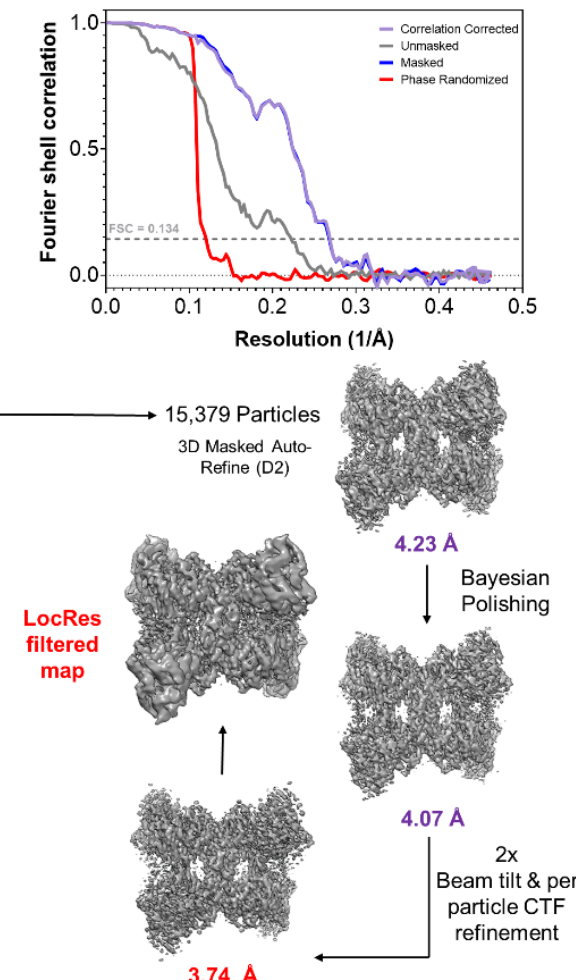

$3.74 \AA$

Extended Data Fig. 7 | Image processing workflow of the GYS1:GYG1 ${ }^{\mathbf{A C D}}+\mathrm{Glc}_{\mathrm{GP}}$ activated state. a, Representative K3 micrograph of the GYS1:GYG1 ${ }^{\Delta \mathrm{CD}}+\mathrm{Glc} 6 \mathrm{P}$ activated state. $\mathbf{b}$, Processing flow chart of the GYS1:GYG1 ${ }^{\Delta C D}+$ Glc6P activated state. c, Angular distribution of the $3.74 \AA$ GYS1:GYG1 ${ }^{\triangle \mathrm{CD}}+\mathrm{Glc} 6 \mathrm{P}$ activated state map. d, Local resolution variation of the $3.74 \AA$

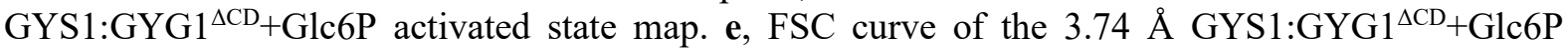
activated state map. 
bioRxiv preprint doi: https://doi.org/10.1101/2021.11.12 468446; this version posted November 13, 2021. The copyright holder for this preprint (which was not certified by peer review) is the author/funder, who has granted bioRxiv a license to display the preprint in perpetuity. It is made available under aCC-BY 4.0 International license.

Structural Basis of Human GYS1 Regulation

a

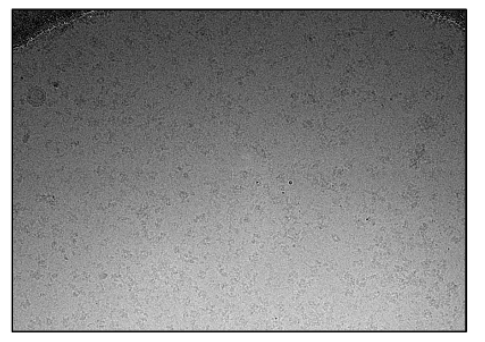

b

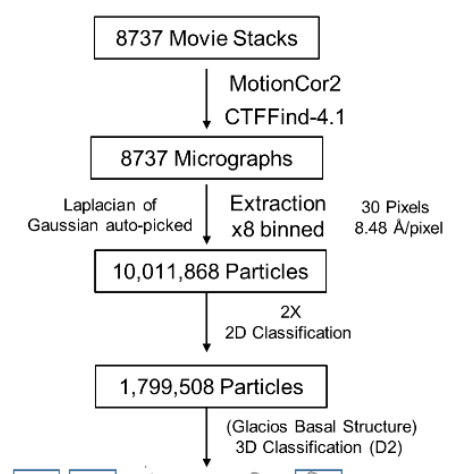

200

荡 $200 \%$

X jom

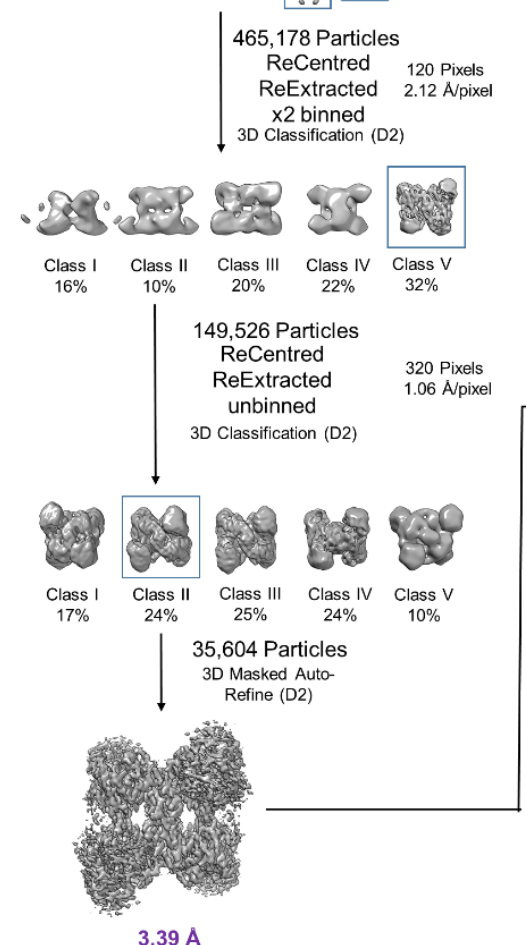

C

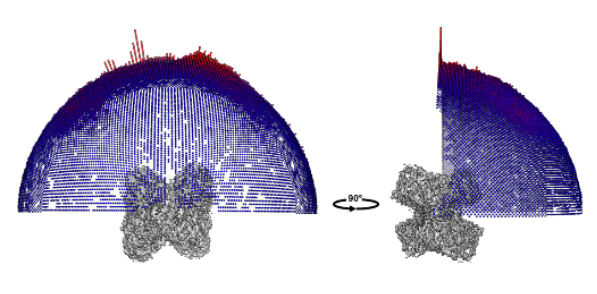

d
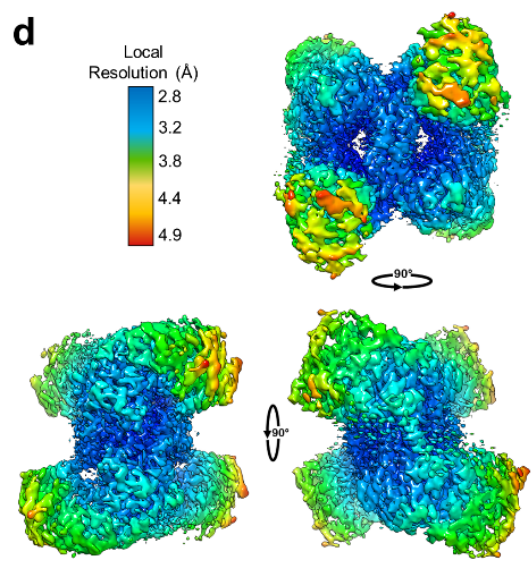

e
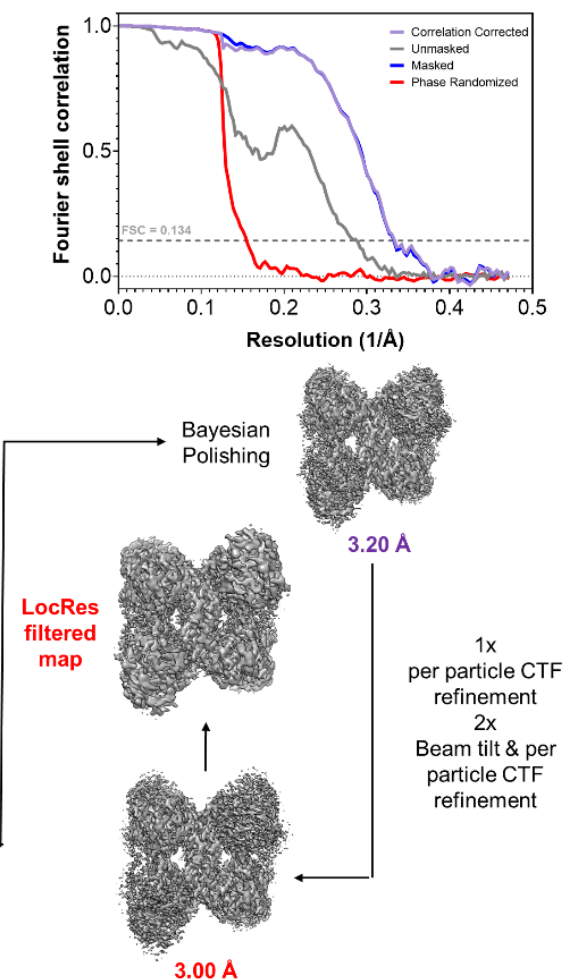

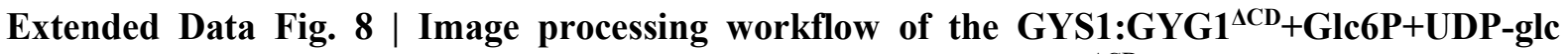
activated state. a, Representative K3 micrograph of the GYS1:GYG1 ${ }^{\triangle C D}+\mathrm{Glc} 6 \mathrm{P}+\mathrm{UDP}$-glc activated state. b, Processing flow chart of the GYS1:GYG1 ${ }^{\Delta \mathrm{CD}+\mathrm{Glc} 6 \mathrm{P}+\mathrm{UDP}-g l c}$ activated state. $\mathbf{c}$, Angular distribution of the $3.00 \AA$ GYS1:GYG1 ${ }^{\Delta \mathrm{CD}}+\mathrm{Glc} 6 \mathrm{P}+\mathrm{UDP}$-glc activated state map. d, Local resolution variation of the $3.00 \AA$ GYS1:GYG1 ${ }^{\triangle \mathrm{CD}}+\mathrm{Glc} 6 \mathrm{P}+\mathrm{UDP}$-glc activated state map. e, FSC curve of the 3.00 $\AA$ GYS1:GYG1 ${ }^{\triangle \mathrm{CD}}+\mathrm{Glc} 6 \mathrm{P}+\mathrm{UDP}$-glc activated state map. 
bioRxiv preprint doi: https://doi.org/10.1101/2021.11.12 468446; this version posted November 13, 2021. The copyright holder for this preprint (which was not certified by peer review) is the author/funder, who has granted bioRxiv a license to display the preprint in perpetuity. It is made available under aCC-BY 4.0 International license.

a

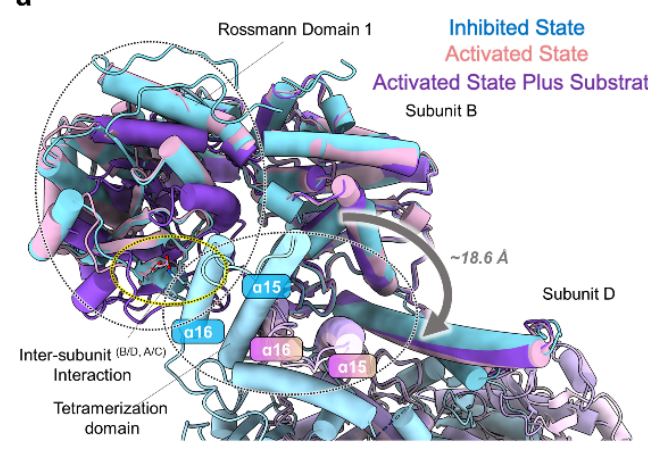

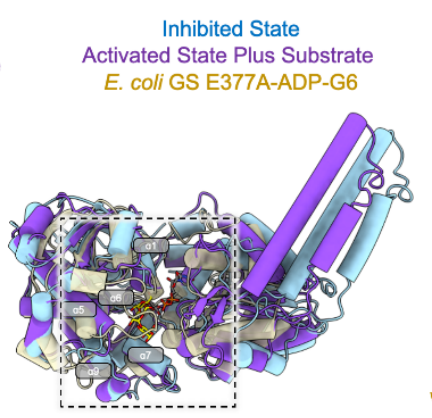
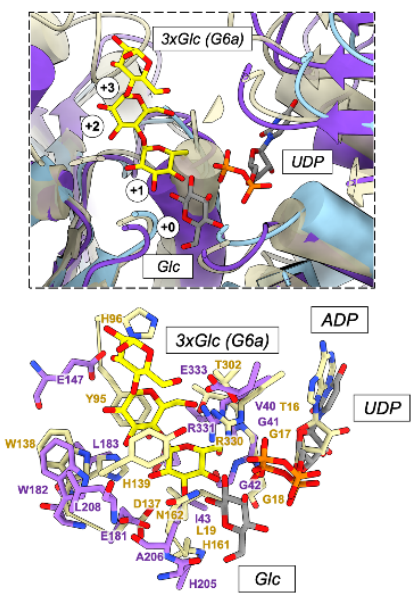

c
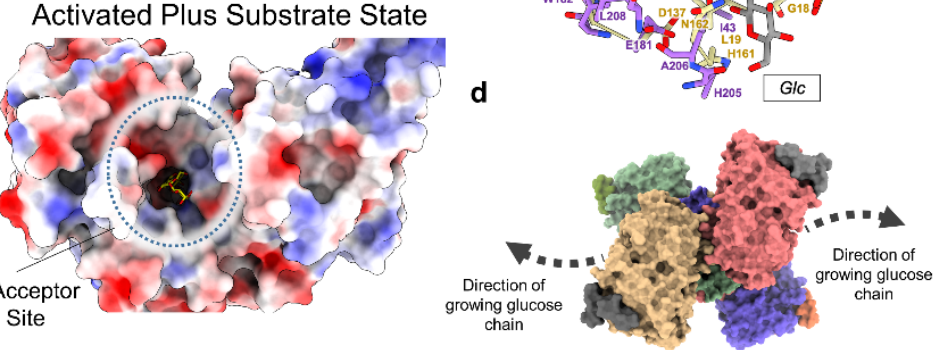

Extended Data Fig. 9 | Structural comparison of the GYS1:GYG1 ${ }^{\triangle C D}$ inhibited and activated states with oligosaccharide bound $E$. coli glycogen synthase. a, Structural alignment of one subunit of the inhibited, activated, and activated plus substrate bound GYS1 structures. Tetramerization helices are highlighted to show relative movement between adjacent subunits within tetrameric hGYS1 b, Structural alignment of the inhibited, activated plus substrate bound states against $E$. coli glycogen synthase bound with three glucose moieties in the active site. The first inset shows the active site of the three structures. The second inset demonstrates conservation of key residues involved in glucan binding c, Electrostatic surfaces of the inhibited and activated plus substrate bound states. The predicted glycogen binding site cleft is highlighted. d, Surface model of the activated state bound to UDP and glucose and the predicted direction of the growing glucose chain. 
a
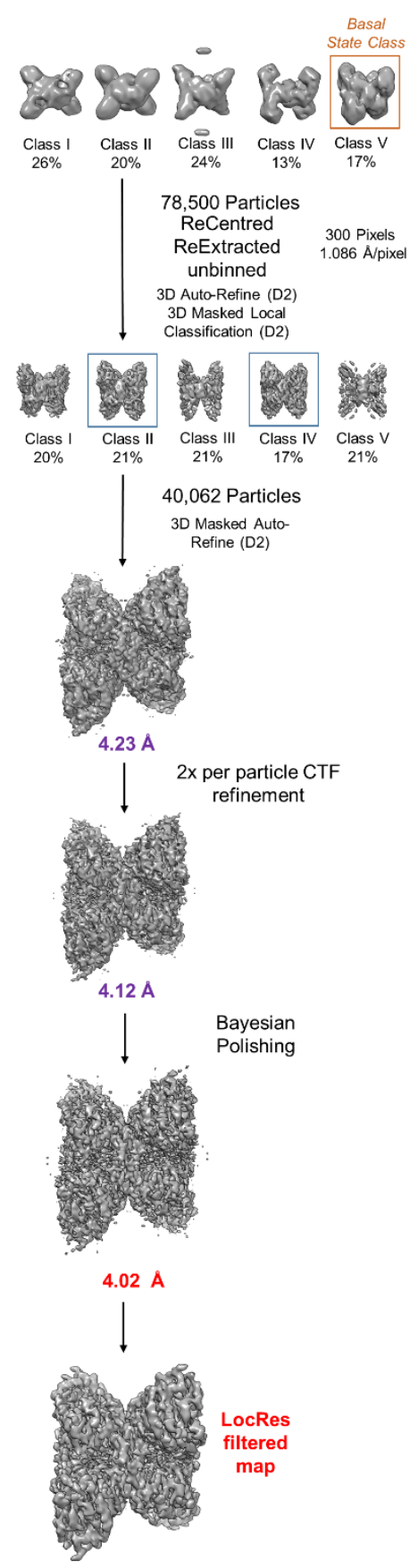

b

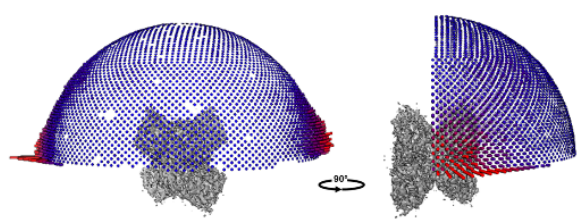

C
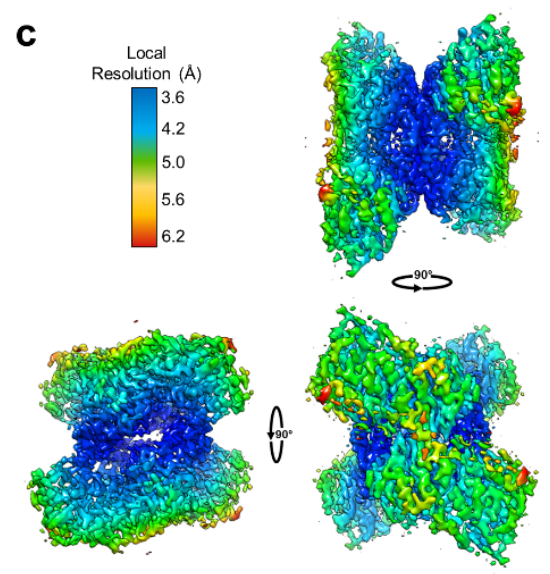

d

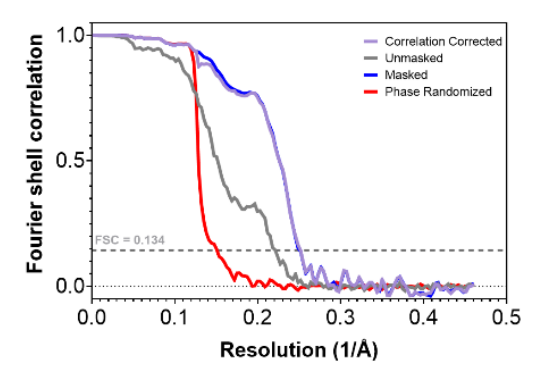

Extended Data Fig. 10 | Image processing workflow of the GYS1:GYG1 ${ }^{\Delta C D}+$ Glc6P inhibited-like state. a, Representative K3 micrograph of the GYS1:GYG1 ${ }^{\Delta \mathrm{CD}}+\mathrm{Glc} 6 \mathrm{P}$ inhibited-like state. b, Processing flow chart of the GYS1:GYG1 ${ }^{\Delta \mathrm{CD}}+\mathrm{Glc} 6 \mathrm{P}$ inhibited- like state. c, Angular distribution of the $4.02 \AA$ GYS1:GYG1 ${ }^{\Delta \mathrm{CD}}+\mathrm{Glc} 6 \mathrm{P}$ inhibited-like state map. $\mathbf{d}$, Local resolution variation of the $4.02 \AA$

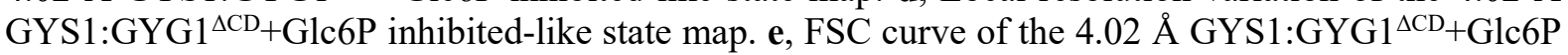
inhibited-like state map. 


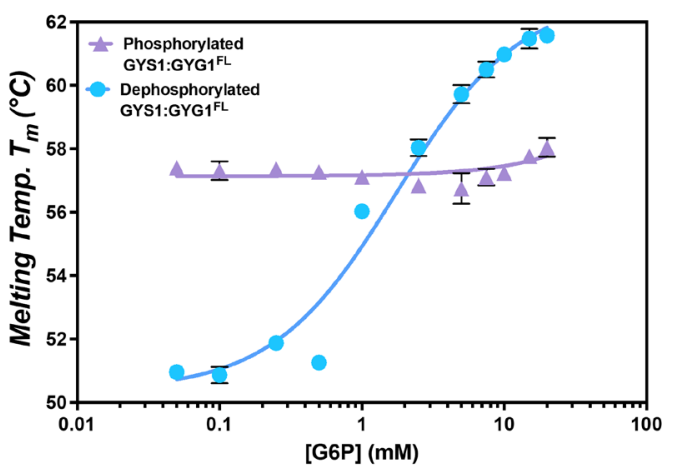

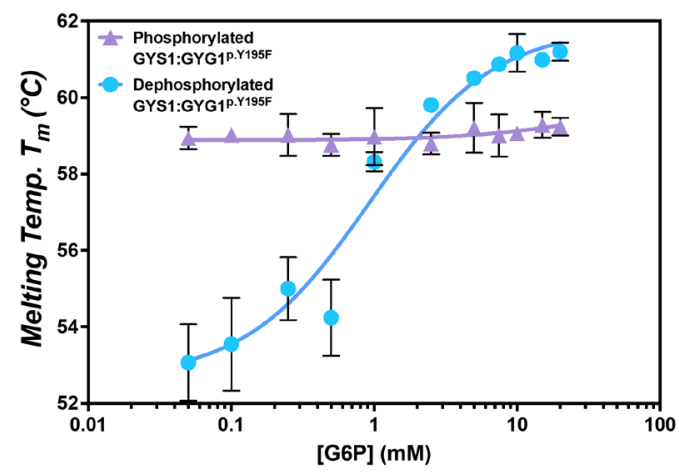

Extended Data Fig. 11 | Thermal shift assay of phosphorylated (as purified) versus dephosphorylated (PP1 treated) GYS1:GYG1 complexes in the presence of increasing concentrations of Glc6P. a, Thermal shift assay of FL GYS1:GYG1 against Glc6P. b, Thermal shift assay of GYS1:GYG1 ${ }^{\text {p.Y195F }}$ against Glc6P. Median melting temperatures and standard deviations are shown $(n=4)$. 
bioRxiv preprint doi: https://doi.org/10.1101/2021.11.12 468446; this version posted November 13,2021 . The copyright holder for this preprint (which was not certified by peer review) is the author/funder, who has granted bioRxiv a license to display the preprint in perpetuity. It is made available under aCC-BY 4.0 International license.

Structural Basis of Human GYS1 Regulation

a Inhibited Like State (+Glc6P): Unique Component (3DVA)Expansion From Tetrameric Interface

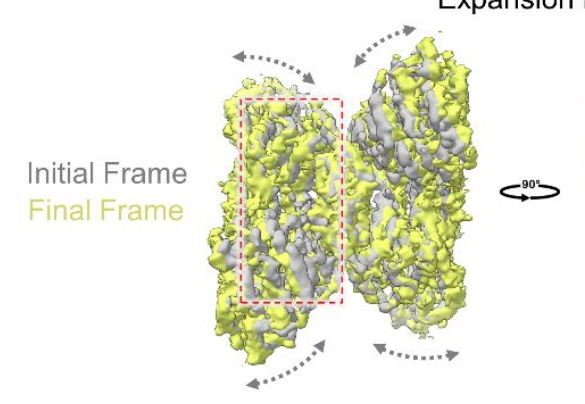

b

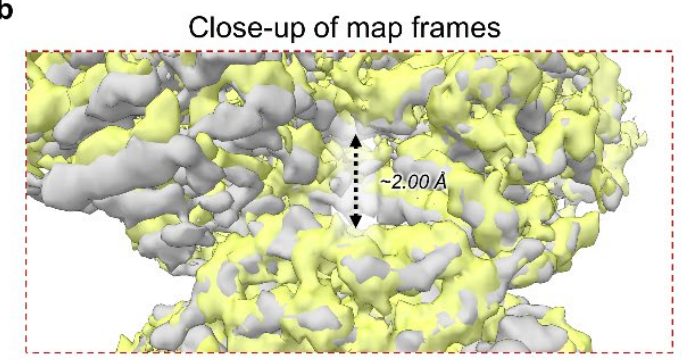

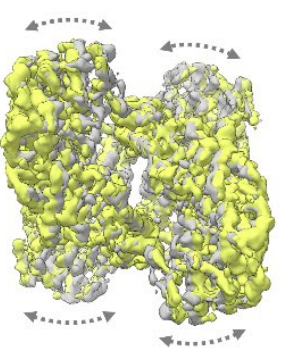

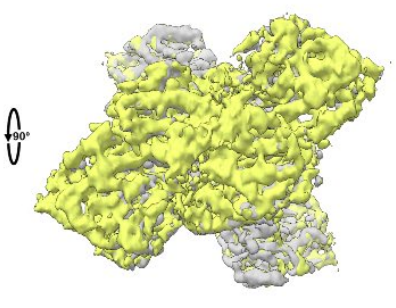

Namdinator fitted models

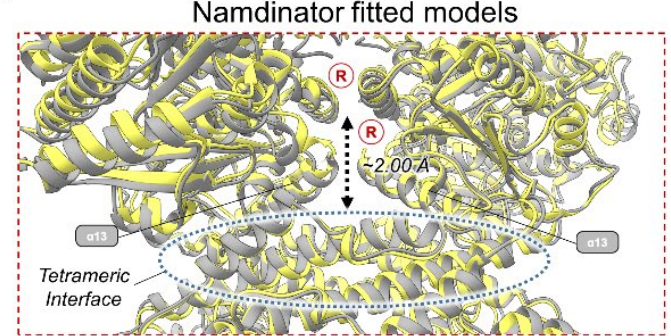

Extended Data Fig. 12 | Unique 3D variability analysis component of the inhibited like Glc6P bound state. a, Alignment of initial and final frames showing a global expansion from the central helical tetrameric interface. b, Close-up of the frames around the allosteric/G6P binding density $\mathbf{c}$, Namdinator fitted models into the initial and final frames showing a clear movement of the alphahelices 13 from both subunits towards the regulatory helices. 
bioRxiv preprint doi: https://doi.org/10.1101/2021.11.12 468446; this version posted November 13,2021 . The copyright holder for this preprint (which was not certified by peer review) is the author/funder, who has granted bioRxiv a license to display the preprint in perpetuity. It is made available under aCC-BY 4.0 International license.
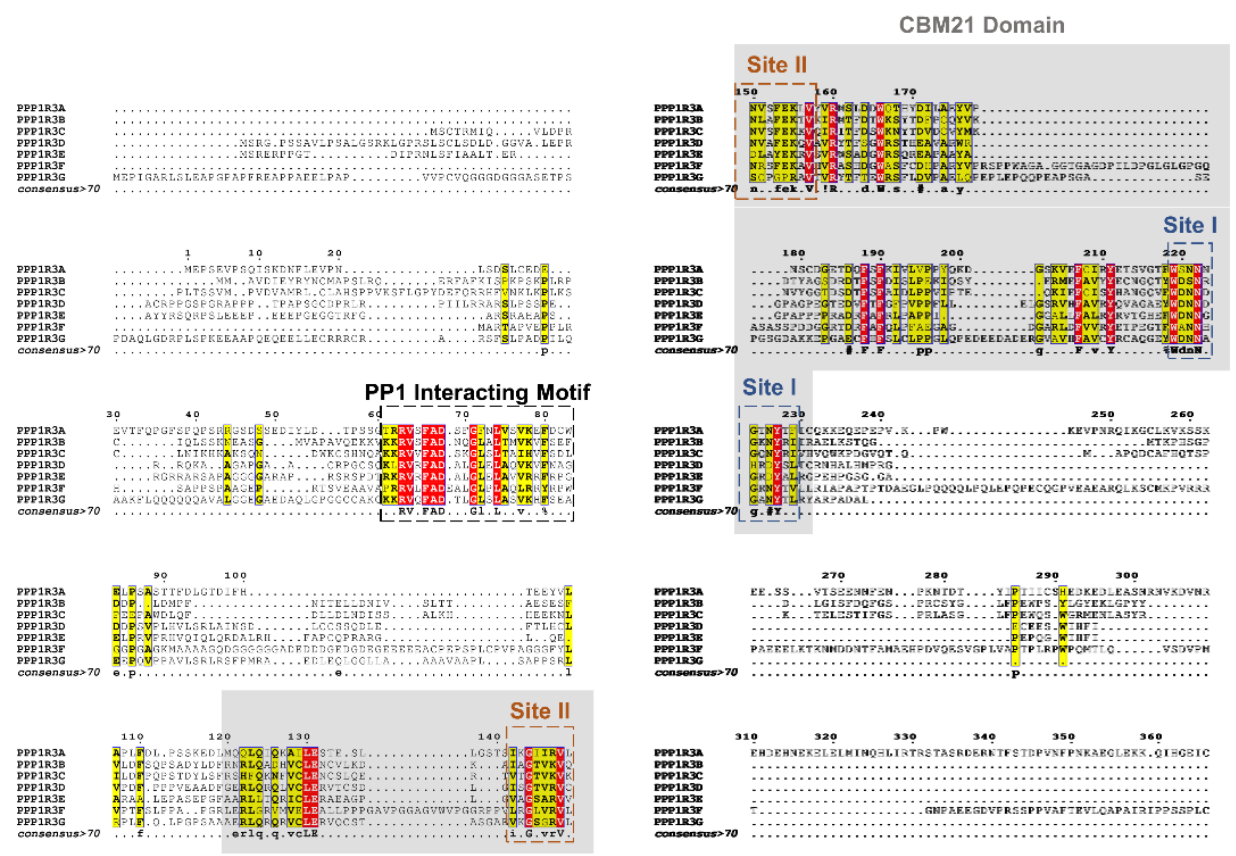

Extended Data Fig. 13 | Sequence alignment of the PP1 regulatory subunits PPP1R3A-G. a, Only the $\mathrm{N}$ terminus and CBM21 domains are considered. PPP1R3A has a long C-terminus to residue 1122 that is not conserved. The PP1 interacting motif along with the sugar binding regions site 1 and site II are highly conserved among the PP1 glycogen recruiting subunits. 